\title{
Additional Comparison of Iced Aerodynamic Measurements on a Swept Wing from Two Wind Tunnels
}

\author{
Sam Lee \\ Vantage Partners, LLC, Cleveland, Ohio, 44135 USA
}

Andy Broeren

NASA John H. Glenn Research Center, Cleveland, Ohio, 44135 USA

Brian S. Woodard University of Illinois at Urbana-Champaign, Urbana, Illinois, 61801 USA

Christopher W. Lum

University of Washington, Seattle, Washington, 98195 USA

and

Timothy G. Smith

FAA William J. Hughes Technical Center, Atlantic City Airport, New Jersey, 08405 USA

\begin{abstract}
Artificial ice shapes of various geometric fidelity were tested on a wing model based on the Common Research Model. Low Reynolds number tests were conducted at Wichita State University's Walter H. Beech Memorial Wind Tunnel utilizing an $8.9 \%$ scale model, and high Reynolds number tests were conducted at ONERA's F1 wind tunnel utilizing a $13.3 \%$ scale model. Several identical geometrically-scaled ice shapes were tested at both facilities, and the results were compared at overlapping Reynolds and Mach numbers. This was to ensure that the results and trends observed at low Reynolds number could be applied and continued to high, near-flight Reynolds number. The data from Wichita State University and ONERA F1 agreed well at matched Reynolds and Mach numbers. The lift and pitching moment curves agreed very well for most configurations. This confirmed results from previous tests with other ice shapes that indicated the data from the low Reynolds number tests could be used to understand iced-swept-wing aerodynamics at high Reynolds number. This allows ice aerodynamics testing to be performed at low Reynolds number facilities with much lower operating costs and generate results that are applicable to flight Reynolds number.
\end{abstract}

\section{Introduction}

The aerodynamic effects of in-flight icing on swept wings is a complex problem that is not well understood. Most of the data available in open literature on the effects of icing on aerodynamics are limited to straight (or un-swept) wings and at Reynolds number much lower than for full-scale aircraft in flight. These previous studies have shown that effects of large leading-edge ice accretions on straight wings are Reynolds and Mach number insensitive [1-4]. Because of this, results obtained during low-Reynolds number tests with subscale models (typically around 1 million) could be applied to full-scale flight Reynolds number (around 10-30 million) without any

Page 1 of 19 (or very little) correction to the data. It was not certain from the data available in the open literature if this was also the case for iced swept-wing. It was also unknown if there were any fundamental differences between iced-aerodynamics on straight wings versus swept wings. On swept wings, the stall mechanism is heavily influenced by strong spanwise flow that is not present in straight wings.

In order to address these shortcomings, a collaborative research effort sponsored by NASA's Advanced Air Transport Technology program, the Office National d'Etudes et Recherches Aérospatiales (ONERA), and the Federal Aviation Administration (FAA) with the support of university and industry partners is currently being conducted in order to develop a systematic understanding of the aerodynamic effects of icing on swept wings [5]. This includes understanding the Reynolds $(R e)$ and Mach $(M)$ number effects, important flowfield physics, and fundamental differences from 2-D, straight wing iced aerodynamics. Another important aspect of this research is determining the level of ice-shape geometric fidelity required for accurate aerodynamic simulation of swept-wing icing effects.

The current study implemented a methodology that was used previously on a straight wing configuration [6]. The baseline aircraft configuration chosen for this study was the CRM65, a $65 \%$ scale version of the Common Research Model (CRM) geometry developed for the American Institute of Aeronautics and Astronautics Drag Prediction Workshop [7]. It was representative of a Boeing 757 sized modern transport aircraft with a geometry that was available to the public. Artificial ice shapes were attached to the leading edge of the CRM65 wing models, and iced aerodynamic performance measurements were taken. The artificial ice-shape geometries were based on those obtained during ice accretion tests at NASA Icing Research Tunnel with CRM65 wing sections [8]. The results from 
the iced aerodynamic tests in this research program have been published in various reports [9-16].

In this research program, iced aerodynamic measurements were obtained with two CRM65 wing models of different geometric scale in separate wind tunnels. An $8.9 \%$-scale model was tested in the Wichita State University (WSU) atmospheric wind tunnel at Reynolds number of 0.8 to 2.4 million. A $13.9 \%$-scale model was tested in the ONERA F1 pressurized wind tunnel at Reynolds number of 1.6 to 11.9 million. The reason for separate tunnel tests was due to the high costs and complexity of testing in the pressurized F1 wind tunnel. The much lower cost and easier test section access of the WSU tunnel allowed numerous configurations to be tested, as well as obtaining detailed flowfield measurements. A more limited set of testing was done in the F1 tunnel, and these results were used to study the effects of Reynolds and Mach number. Although the maximum Reynolds number obtainable in F1 was 11.9 million (vs. 20-30 for CRM65 in hold condition), it was deemed sufficiently high to study Reynolds number effects.

In order to have better confidence in applying the low Reynolds number results from the WSU tunnel to the high Reynolds number results from F1, comparisons were made between the WSU and F1 data at overlapping or matched Reynolds number with identical ice shapes. Ideally, even for wing models of different scale in different wind tunnels, if the Reynolds and Mach numbers are matched, then the aerodynamic performance should match as well. However, past studies using similar approaches have shown that this is not always the case, especially for clean wing configuration $[2,4]$. Some of the reasons were wing and airfoil geometries not being exactly identical, different aspect ratios of 2D models, and models of different scales having different blockage effects in the test section. Another important factor was not matching Mach number at matched Reynolds number. Iced configurations typically yielded much better results because iced shapes tend to mask some of these effects. However, matching the aerodynamic performance of both clean and ice configurations at overlapping Reynolds number is desired.

In the current study with the CRM65 wing, careful consideration was used to minimize the effects listed above in order to have a better match of the data between the low and high Reynolds number tests using models of different geometric scale. In the initial tests at WSU and F1 wind tunnels, several identical ice shape configurations of various geometric fidelity were tested at both facilities and the results were compared at overlapping and matched Reynolds and Mach numbers. The results from this comparison were reported in Lee, et al. [17]

The results showed very good overall comparisons of both clean and iced configurations between the data acquired at WSU and F1 at matched or similar $R e$ and $M$. The lift and pitching moment curves agreed very well for most configurations. There appeared to be 0.2 $0.3^{\circ}$ offset in the angle of attack between the WSU and F1 data, possibly due to different flow angularities in the test sections of the two facilities. There was also an offset of approximately $10 \mathrm{drag}$ counts in the drag values between the two facilities, possibly from experimental uncertainties.

For iced configurations, the trends observed at low Reynolds number (WSU test) could be extended to high Reynolds number (F1). In fact, for ice shapes with highly complex 3D features, such as scallop or lobster-tail shapes, the lift-based performance values can be used directly at high Reynolds number because there was no $\operatorname{Re}$ or $M$ effect. For smoother, quasi-2D ice shapes, there were slight

Page 2 of 19
Reynolds number effects, but these could be largely eliminated with the addition of roughness grits on the ice shapes. In all iced configurations there were slight $R e$ effects in the drag-based parameters, so the trends from low Re tests can be applied to higher $R e$, but the values need slight correction.

Since the last reported work [17], additional ice shape configurations were tested in both WSU and F1 tunnels. This paper presents the aerodynamic results from these tests to determine if these ice shapes follow the same trends identified during the previous tests with the CRM65 wing. If continued good agreement can be shown between WSU and F1 tunnel measurements, then the results from the low Reynolds number tests could be applied to high, near-flight Reynolds number with continued confidence.

\section{Wind Tunnel Facilities, Models, and Experimental Methods}

\section{Wind Tunnel Facilities}

The low Reynolds number tests were carried out in the Walter $\mathrm{H}$. Beech Wind Tunnel at Wichita State University (WSU), in Wichita, Kansas. The WSU tunnel is an atmospheric, closed-return, subsonic tunnel with a 7x10 ft. test section. The high Reynolds number tests were carried out in the ONERA F1 wind tunnel located in Mauzac, France. The F1 tunnel is a pressurized, closed return tunnel with an $11.5 \times 14.8 \mathrm{ft}$ test section.

The Reynolds and Mach number combinations are shown in Table 1 for the low Reynolds number test at WSU and in Table 2 for the high Reynolds number test at F1. Reynolds number of $1.6 \times 10^{6}$ was run in both WSU and F1. However, at this Reynolds number, Mach number was 0.18 in the WSU tunnel and 0.09 in the F1 tunnel. The F1 tunnel cannot operate at below atmospheric pressures and does not have the ability to operate at cryogenic temperatures, so both $R e$ and $M$ cannot be matched when comparing to an atmospheric tunnel running a smaller chord model, as was the case in this study. In this paper (Re $\left.=1.6 \times 10^{6}, M=0.18\right)$ condition from the WSU tunnel is primarily compared to $\left(\operatorname{Re}=1.6 \times 10^{6}, M=0.09\right)$ and $\left(\operatorname{Re}=2.7 \times 10^{6}, M=0.18\right)$ conditions from F1 tunnel and are highlighted yellow in Tables 1 and 2. Also, not all of the conditions shown in Table 2 were run for all iced configurations due to time constraints during the F1 tests.

Table 1. Reynolds and Mach number conditions for WSU Tunnel.

\begin{tabular}{|c|c|c|c|}
\hline Reynolds Number & Mach Number & $\boldsymbol{p}_{\boldsymbol{0}}(\mathbf{p s i})$ & $\boldsymbol{q}_{\infty}(\mathbf{p s i})$ \\
\hline $\mathbf{0 . 8 x 1 0}^{\mathbf{6}}$ & 0.09 & 14.0 & 0.08 \\
\hline $\mathbf{1 . 6 x 1 0}^{\mathbf{6}}$ & 0.18 & 14.0 & 0.30 \\
\hline $\mathbf{2 . 4 x 1 0}^{\mathbf{6}}$ & 0.27 & 14.0 & 0.69 \\
\hline
\end{tabular}


Table 2. Reynolds and Mach number conditions for F1 Tunnel. (Pressure are in psi.)

\begin{tabular}{|c|c|c|c|c|c|}
\hline \multirow{2}{*}{\begin{tabular}{c|} 
Reynolds \\
Number \\
\end{tabular}} & \multicolumn{5}{|c|}{ Mach Number } \\
\hline & 0.09 & 0.18 & 0.23 & 0.27 & 0.34 \\
\hline $1.6 \times 10^{6}$ & $\begin{array}{l}p_{0}=18.9 \\
q_{\infty}=0.17\end{array}$ & & & & \\
\hline $2.7 \times 10^{6}$ & $\begin{array}{l}p_{0}=30.5 \\
q_{\infty}=0.17\end{array}$ & $\begin{array}{l}p_{0}=16.0 \\
q_{\infty}=0.35\end{array}$ & & & \\
\hline $4.0 \times 10^{6}$ & $\begin{array}{l}p_{0}=46.4 \\
q_{\infty}=0.26\end{array}$ & $\begin{array}{l}p_{0}=23.2 \\
q_{\infty}=0.52\end{array}$ & $\begin{array}{l}p_{0}=18.9 \\
q_{\infty}=0.65\end{array}$ & $\begin{array}{l}p_{0}=16.0 \\
q_{\infty}=0.78\end{array}$ & \\
\hline $6.8 \times 10^{6}$ & & $\begin{array}{l}p_{0}=39.2 \\
q_{\infty}=0.88\end{array}$ & $\begin{array}{c}p_{0}=31.9 \\
q_{\infty}=1.1\end{array}$ & $\begin{array}{c}p_{0}=27.6 \\
q_{\infty}=1.3\end{array}$ & $\begin{array}{c}p_{0}=21.8 \\
q_{\infty}=1.7\end{array}$ \\
\hline $9.6 \times 10^{6}$ & & $\begin{array}{c}p_{0}=55.1 \\
q_{\infty}=1.2\end{array}$ & & & \\
\hline $11.9 \times 10^{6}$ & & & $\begin{array}{c}p_{0}=55.1 \\
q_{\infty}=2.0\end{array}$ & & \\
\hline
\end{tabular}

The wind-tunnel models were installed on a turntable that provided angle of attack actuation in both facilities. The load measurements were obtained a using six-component force balance located beneath the turntable floor.

\section{Wind-Tunnel Models}

The wing models used in this study were geometrically scaled versions of the CRM65 semi-span wing. The F1 model was geometrically equivalent to the WSU model but scaled up by a factor of 1.5. Table 3 shows the summary of geometric parameters of these models, and Fig. 1 shows the planform with key dimensions. Other than the geometric scale, the wing geometries were identical.

Table 3. Wing model geometry parameters.

\begin{tabular}{|c|c|c|}
\hline Wing Parameter & WSU & F1 \\
\hline Scale & $8.9 \%$ & $13.3 \%$ \\
\hline Span & $5 \mathrm{ft}(1.52 \mathrm{~m})$ & $7.5 \mathrm{ft}(2.28 \mathrm{~m})$ \\
\hline$M A C$ & $1.39 \mathrm{ft}(0.42 \mathrm{~m})$ & $2.08 \mathrm{ft}(0.63 \mathrm{~m})$ \\
\hline Area & $6.01 \mathrm{ft}^{2}\left(0.56 \mathrm{~m}^{2}\right)$ & $13.55 \mathrm{ft}^{2}\left(1.26 \mathrm{~m}^{2}\right)$ \\
\hline Volume & $0.617 \mathrm{ft}^{3}\left(0.017 \mathrm{~m}^{3}\right)$ & $2.09 \mathrm{ft}^{3}\left(0.059 \mathrm{~m}^{3}\right)$ \\
\hline Aspect Ratio & \multicolumn{2}{|c|}{8.3} \\
\hline Taper Ratio & \multicolumn{2}{|c|}{0.23} \\
\hline Root Chord & $2.25 \mathrm{ft}(0.69 \mathrm{~m})$ & $3.38 \mathrm{ft}(1.03 \mathrm{~m})$ \\
\hline Tip Chord & $0.52 \mathrm{ft}(6.19 \mathrm{~m})$ & $0.77 \mathrm{ft}(9.28 \mathrm{~m})$ \\
\hline Root $\alpha$ & \multicolumn{2}{|c|}{$4.4^{\circ}$} \\
\hline $\operatorname{Tip} \alpha$ & \multicolumn{2}{|c|}{$-3.8^{\circ}$} \\
\hline 1/4-chord $\Lambda$ & \multicolumn{2}{|c|}{$35^{\circ}$} \\
\hline Leading edge $\Lambda$ & \multicolumn{2}{|c|}{$37.2^{\circ}$} \\
\hline $\begin{array}{l}\text { Location of rotation } \\
\text { center }\end{array}$ & $\begin{array}{c}x=19.37 \text { in }(5.90 \mathrm{~m}) \\
z=0 \text { in }\end{array}$ & $\begin{array}{c}x=29.05 \text { in }(8.85 \mathrm{~m}) \\
z=0 \text { in }\end{array}$ \\
\hline $\begin{array}{l}\text { Location of } 0.25 \\
\qquad M A C\end{array}$ & $\begin{array}{c}x=17.49 \text { in }(5.33 \mathrm{~m}) \\
z=0 \text { in }\end{array}$ & $\begin{array}{c}x=26.23 \text { in }(7.99 \mathrm{~m}) \\
z=0 \text { in }\end{array}$ \\
\hline
\end{tabular}

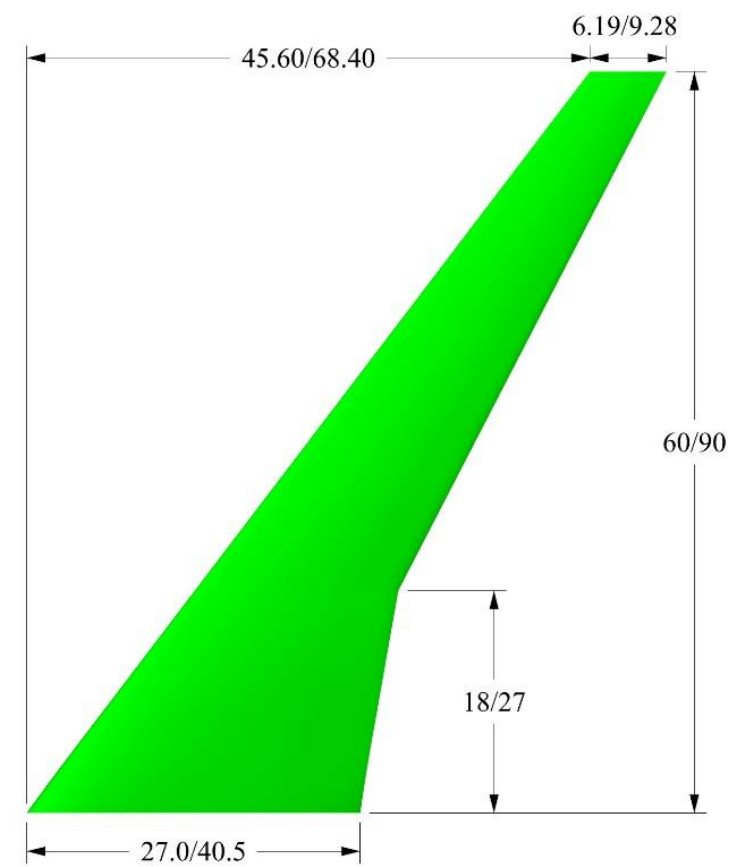

Figure 1. WSU and F1 CRM65 semi-span wing planform with key dimensions labeled in inches (WSU on left and F1 on right).

Both WSU and F1models featured a removable leading edge (RLE) design that facilitated a rapid and repeatable installation of artificial ice shapes. One version of the RLE consisted of the clean airfoil contour and was used for testing of the clean (i.e. un-iced) wing configurations. Another version had the leading edge cut out so that artificial ice shapes could be bolted on. The models were installed vertically on turn tables in both of the tunnels, as shown in Fig. 2. Non-metric circular splitter plates were used to place the models above the test section floor boundary layer. Both of the models were instrumented with surface pressure taps in order to obtain pressure distributions.

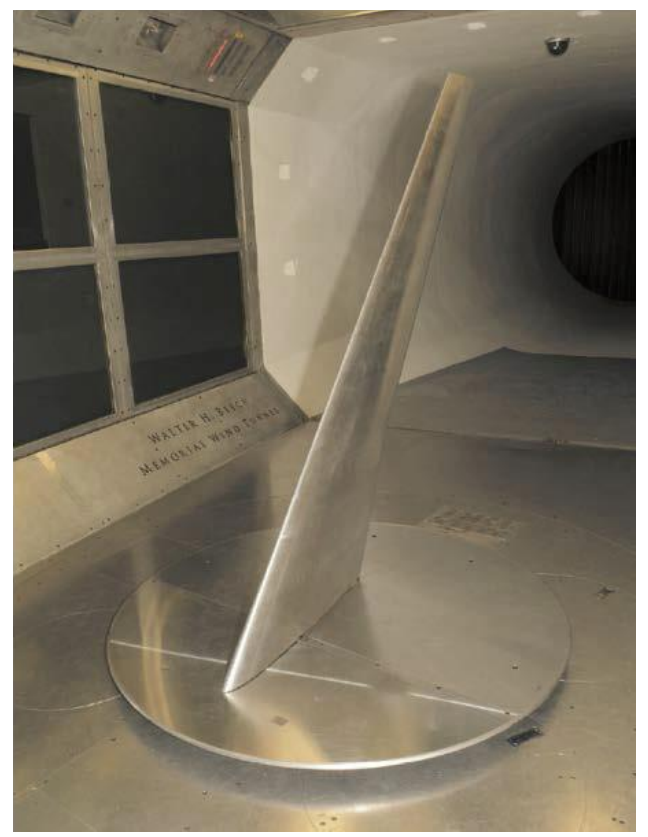

a) WSU model 


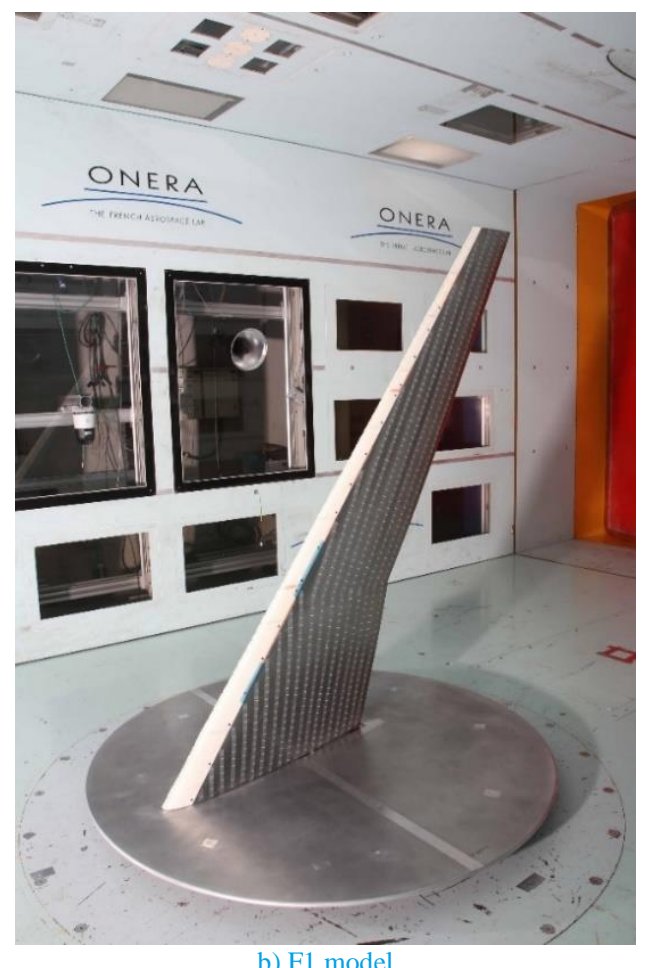

b) F1 model

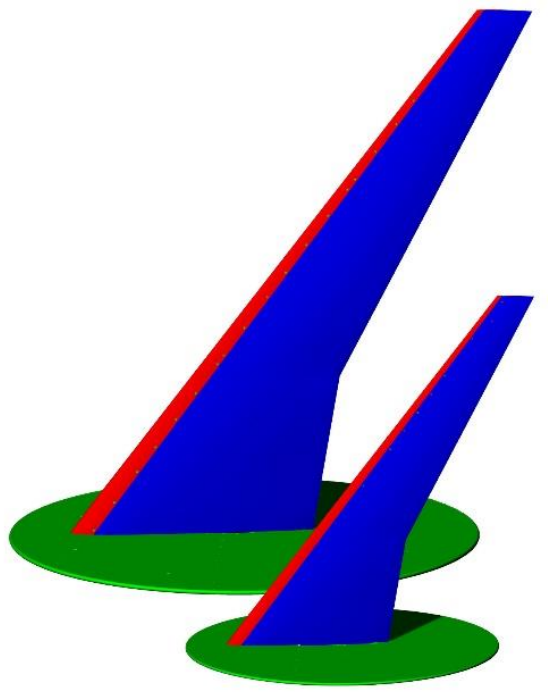

c) Models compared at same scale

Figure 2. CRM65 semi-span wing models.

\section{Aerodynamic Measurements}

The primary aerodynamic measurements $\left(C_{L}, C_{M}\right.$, and $\left.C_{D}\right)$ were obtained by the six-component force balance used at the two facilities. The pitching moment coefficients were calculated about the 0.25 mean aerodynamic chord $(M A C)$ location. The measurements from the WSU tunnel were obtained at paused angles of attack at every $0.25^{\circ}$ to $1^{\circ}$, while the measurements from the F1 tunnel were obtained at continuous $0.1 \% \mathrm{sec}$ angle of attack sweep. The F1 data were conditionally averaged into $0.5^{\circ}$ angle of attack increments using $\mathrm{a} \pm 0.15^{\circ}$ window based on the geometric (uncorrected) angle of attack. For example, data acquired over the interval $3.85^{\circ} \leq \alpha \leq 4.15^{\circ}$ were used to create conditionally averaged values for $\alpha=4^{\circ}$. This was required because the boundary layer becomes quite unsteady as the iced wing approaches stall and a temporal averaging of the data was required to smooth the data near stall.

The WSU measurements were corrected with the standard procedure for 3-D models described in Pope, et al. [18] A more detailed description of the corrections can be found in the WSU facility report [19]. The F1 measurements were corrected with an in-house ONERA method [20]. Comparison of the data corrected with the Pope and F1 in-house methods were made in Lee, et al. [17], and they were found to be nearly identical.

The uncertainties for the aerodynamic coefficients are shown in Tables 4 and 5. They were calculated using the "root sum square" method outlined in Coleman and Steele [21] and Kline and McClintock [22]. Detailed assumptions and analysis used to generate the uncertainties for these tests can be found in Woodard, et al. [9] (for WSU) and Torz-Dupuis [20] (for F1). It is important to note that while the uncertainties for the F1 test appear large, they are for $q_{\infty}=$ 0.35 psi. At these low dynamic pressures, the force balance loads are quite low compared to the full range of the force balance.

Table 4. WSU tunnel aerodynamic coefficient uncertainties. (Clean model, $\left.\operatorname{Re}=1.6 \times 10^{6}, M=0.18, \alpha=5^{\circ}, q_{\infty}=0.30 \mathrm{psi}\right)$.

\begin{tabular}{|c|c|c|c|}
\hline Variable & $\begin{array}{c}\text { Reference } \\
\text { Value }\end{array}$ & $\begin{array}{c}\text { Absolute } \\
\text { Uncertainty }\end{array}$ & $\begin{array}{c}\text { Relative } \\
\text { Uncertainty (\%) }\end{array}$ \\
\hline$C_{L}$ & 0.5566 & 0.0047 & 0.84 \\
\hline$C_{D}$ & 0.0220 & 0.0013 & 6.12 \\
\hline$C_{M}$ & -0.2169 & 0.0020 & 0.92 \\
\hline
\end{tabular}

Table 5. F1 tunnel aerodynamic coefficient uncertainties. (Clean model, $R e=$ $\left.2.7 \times 10^{6}, M=0.18, \alpha=5^{\circ}, q_{\infty}=0.35 \mathrm{psi}\right)$.

\begin{tabular}{|c|c|c|c|}
\hline Variable & $\begin{array}{c}\text { Reference } \\
\text { Value }\end{array}$ & $\begin{array}{c}\text { Absolute } \\
\text { Uncertainty }\end{array}$ & $\begin{array}{c}\text { Relative } \\
\text { Uncertainty (\%) }\end{array}$ \\
\hline$C_{L}$ & 0.5749 & 0.0164 & 2.85 \\
\hline$C_{D}$ & 0.0202 & 0.0035 & 17.37 \\
\hline$C_{M}$ & -0.2285 & 0.0083 & 3.63 \\
\hline
\end{tabular}

\section{Artificial Ice Shapes}

The artificial ice shapes were manufactured using stereo-lithography (SLA) 3D printing process. The ice shape geometries used in this study were obtained from laser scans of ice shapes obtained during NASA Icing Research Tunnel tests with three CRM65 wing sections (from $y / b=0.20,0.64$, and 0.83) with full-scale leading edge [8]. These ice shape segments were interpolated and extrapolated over the entire span of the wing, then geometrically scaled to fit the subscale WSU and F1 models [23]. Reduced geometric fidelity versions of these ice shapes, as well as those generated using computational ice prediction code, were tested as well. They will de described in more detail later in this section. 
All of the artificial ice shapes presented in this paper originated from two icing conditions that were tested in the IRT. Figure 3 shows the photographs of the ice shapes generated from these two conditions. The "Maximum Scallop" ice shape was derived from the icing condition tested in Broeren et al. [8] that produced the largest "scallop" features and is shown in Table 6. There are two conditions shown in Table 6 for the "Max Scallop" condition. "Flight Reference" refers to the condition for the CRM65 aircraft in hold condition at 232 knots. Unfortunately, because of the tunnel blockage and model loads, the IRT could not be operated at this speed, and a scaled condition at reduced speed (but still generating geometrically equivalent ice shape), referred to as "IRT Scale" was used to generate the ice shapes.

The icing conditions (Table 7) used to generate the "WB33" ice shape was obtained from the a condition that had identical angle of attack and airspeed as Maximum Scallop condition but with the LWC, MVD, temperature, and accretion time consistent with FAA Appendix $\mathrm{C}$ icing conditions. This resulted in a glaze ice shape with a highly complex 3D morphology but without any "scallop" features. The "WB33" condition also required conditional scaling in order to test in the IRT. More details concerning these two ice shapes can be found in Broeren, et al. [8]
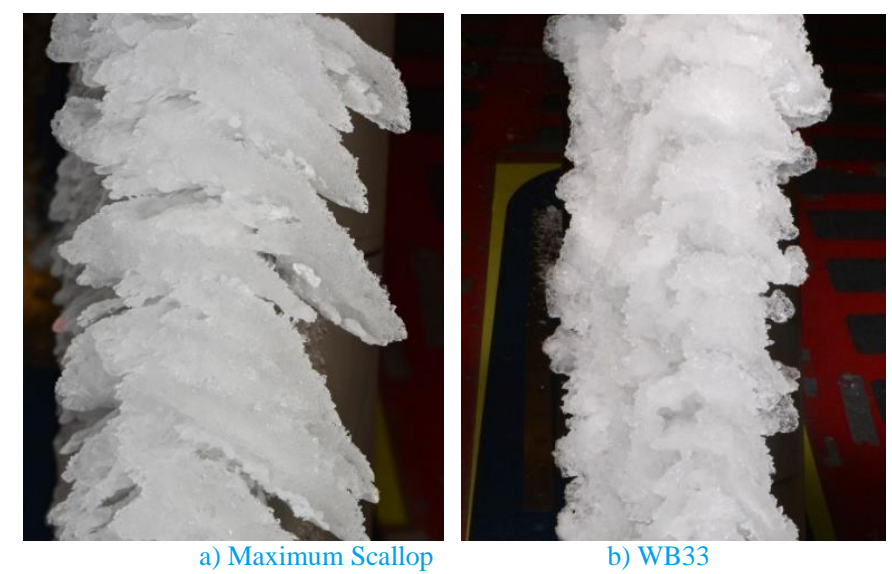

b) WB33

Figure 3. Front-view photographs of IRT ice shapes used to create artificial ice shapes from $y / b=0.64$ location on CRM65 wing.

Table 6. Summary of icing condition for Max Scallop ice shape.

\begin{tabular}{|c|c|c|c|c|c|c|}
\hline Condition & $\begin{array}{c}\boldsymbol{\alpha} \\
\left({ }^{\circ}\right)\end{array}$ & $\begin{array}{c}\boldsymbol{V} \\
(\mathbf{k t s})\end{array}$ & $\begin{array}{c}\boldsymbol{T}_{\boldsymbol{o}} \\
\left({ }^{\circ} \mathbf{C}\right)\end{array}$ & $\begin{array}{c}\boldsymbol{M V D} \\
(\boldsymbol{\mu} \mathbf{m})\end{array}$ & $\begin{array}{c}\boldsymbol{L W C} \\
\left(\mathbf{g} / \mathbf{m}^{\mathbf{3}}\right)\end{array}$ & $\begin{array}{c}\text { Time } \\
(\mathbf{m i n})\end{array}$ \\
\hline Flight Ref. & 3.7 & 232 & -3.0 & 20 & 0.55 & 29 \\
\hline IRT Scaled & 3.7 & 130 & -6.3 & 25 & 1.0 & 29 \\
\hline
\end{tabular}

Table 7. Summary of icing conditions for WB33 ice shape.

\begin{tabular}{|c|c|c|c|c|c|c|}
\hline Condition & $\begin{array}{c}\alpha \\
\left({ }^{\circ}\right)\end{array}$ & $\begin{array}{c}\boldsymbol{V} \\
(\mathbf{k t s})\end{array}$ & $\begin{array}{c}\boldsymbol{T}_{\boldsymbol{o}} \\
\left({ }^{\circ} \mathrm{C}\right)\end{array}$ & $\begin{array}{c}\boldsymbol{M V D} \\
(\boldsymbol{\mu} \mathbf{m})\end{array}$ & $\begin{array}{c}\boldsymbol{L W C} \\
\left(\mathbf{g} / \mathbf{m}^{\mathbf{3}}\right)\end{array}$ & $\begin{array}{c}\text { Time } \\
(\mathbf{m i n})\end{array}$ \\
\hline Flight Ref. & 3.7 & 232 & 1.1 & 20 & 0.51 & 45 \\
\hline IRT Scaled & 3.7 & 130 & -3.1 & 27 & 0.91 & 45 \\
\hline
\end{tabular}

The CAD drawings of the ice shape configurations compared in this paper are shown in Fig. 4. All of these ice shape are from a spanwise section near $y / b=0.60$. In Lee, et al. [17], the term "High Fidelity" was used to describe an artificial ice shape where an attempt was Page 5 of 19 made to maintain as much of the localized 3D features (as shown in Fig. 3) from the original ice shape scan as possible. All of the "High Fidelity" ice shapes that were tested in this research program were presented previously in Lee, et al. [17], and are not presented in this paper. This paper presents the results from additional reduced geometric fidelity ice shapes and ice shapes obtained using ice shape prediction code from the "Max Scallop" and "WB33" icing conditions.

In Fig. 4, the term "3D Smooth" is used to describe an artificial ice shape where the "3D High Fidelity" shape is smoothly lofted over the span using the largest ice shape features. While the "3D Smooth" shape is three dimensional in nature over the span of the wing, locally it is essentially 2D. Another important feature is that most of the "High Fidelity" shape fits inside the "3D Smooth" shape since it is a loft of the largest features of the former shape. The "Max Scallop 3D Smooth" shape was tested with hemispherical roughness 3D printed directly onto the surface (Fig. 4b). On the WSU model, the height of the hemisphere was 0.010 inch. On the F1 model, the height was $0.015 \mathrm{inch}$. These roughness size provided heights that nearly matched the $3 \mathrm{~mm}$ roughness height suggested in the FAA Advisory Circular 25-25A [24] when scaled geometrically. The "WB33 3D Smooth" shape (Fig. 4g) was tested with and without surface roughness grits. The roughness consisted of silicon-carbide grit applied to the surface of the ice shape using epoxy. For the WSU model, 60-grit was used, and for the F1 model, 46-grit was used. Again, these sizes were chosen to match the $3 \mathrm{~mm}$ roughness height suggested in the FAA Advisory Circular 25-25A.

The "LEWICE" shapes (Figs. 4c, 4d, and 4h) were obtained by running NASA's ice prediction code LEWICE3D with the icing conditions shown in Tables 6 and 7. "LEWICE IFB (Iced Flight Baseline)" shapes were generated by running LEWICE3D with the CRM65 wing in its entirety using the Flight Reference conditions. "LEWICE IRT" shape was obtained by running LEWICE3D with the three CRM65 wing section models in the IRT (using IRT Scaled condition). The resulting ice shapes were then interpolated over the CRM65 wing in the same manner as the "3D Smooth" ice shapes. The "LEWICE" shapes had morphology similar to that of the "3D Smooth" shapes in that while they varied along the span, locally they were 2D. The "LEWICE" shapes were only tested with roughness grit.

A simplified scallop shape geometry termed "Artificial Scallop Ice" is shown in Figs. 4e and 4f. It was created by cutting slices into the "3D Smooth" version of the "Max Scallop" ice shape in order to create a simple geometry where the spacing, angle, and orientation of the gaps between the scallop features can be studied. The "Simple Horn Ice" (Fig. 4i) was a representation of the "WB33" ice shape simplified into a simple upper surface horn geometry. This version of the artificial ice shape was created to perform a parametric study on the effect of the size, location, and angle of the upper surface horn feature on swept wing iced aerodynamics. The "Artificial Scallop" shapes were not tested with roughness grits. The "Simple Horn" shapes were tested with and without roughness grits.

A detailed description of how "3D Smooth" ice shapes were generated can be found in Camello, et al. [23,25] Details of "Max Scallop" ice shapes presented in this paper can be found in Woodard, et al. [14], and details of the "WB33" ice shapes can be found in Broeren, et al. [15] 


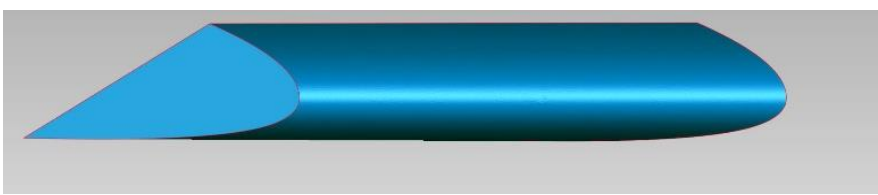

a) Clean wing.

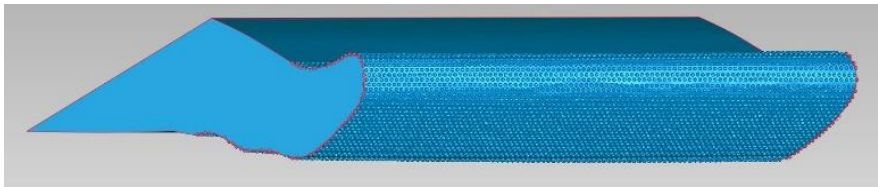

b) Max Scallop 3D Smooth with Hemisphere Roughness

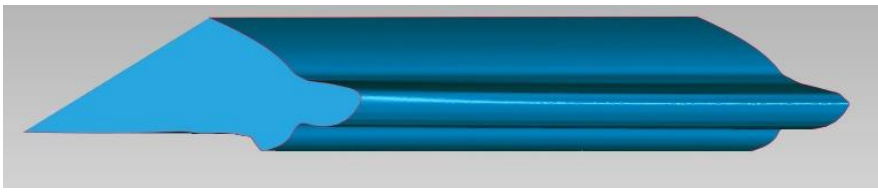

c) Max Scallop LEWICE IFB (tested with grit)

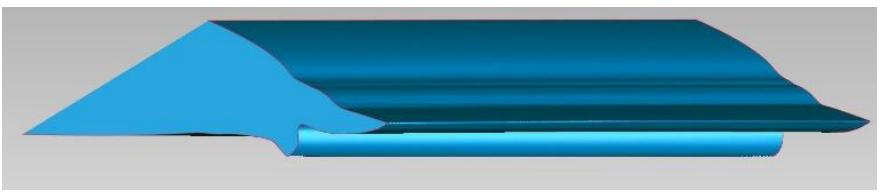

d) Max Scallop LEWICE IRT (tested with grit)

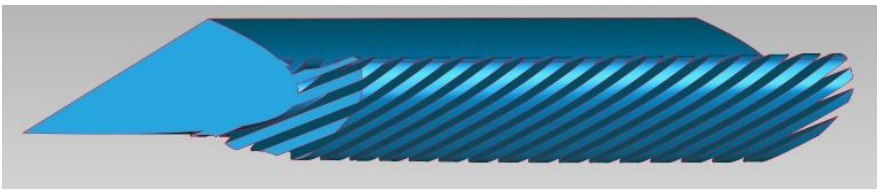

e) Max Scallop Artificial Scallop with Small Gap

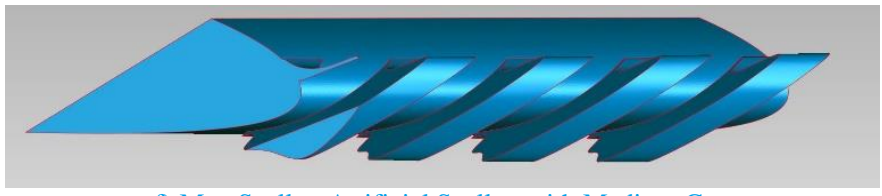

f) Max Scallop Artificial Scallop with Medium Gap

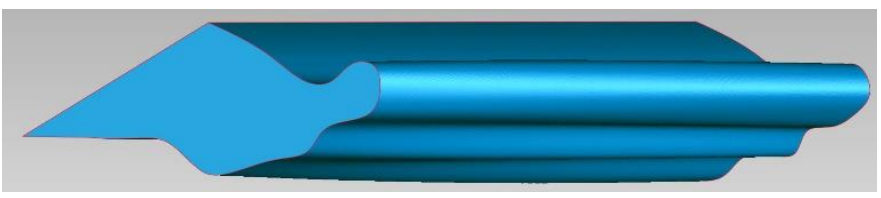

g) WB33 3D Smooth (tested with and without grit)

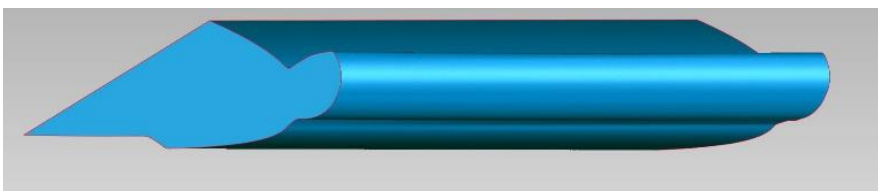

h) WB33 LEWICE IFB (tested with grit)

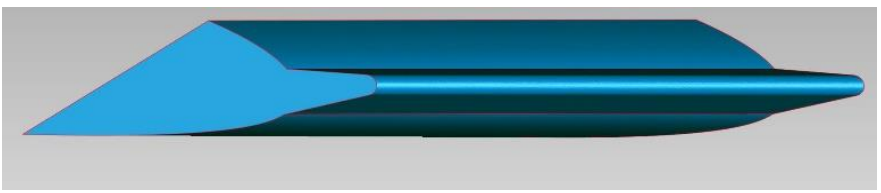

i) WB33 Simple Horn (tested with and without grit)

Figure 4. Artificial ice shapes geometries compared between WSU and F1 tunnels.

Page 6 of 19

\section{Results and Discussions}

The comparisons shown in this paper were from the 10 additional cases where identical simulated ice shape configurations were tested in both WSU and F1 tunnels and not reported in Lee, et al. [17]

\section{Clean Configuration}

Figure 5 shows the clean model lift, pitching moment, and drag curves for the WSU and F1 models at matched $R e$ and $M$. As stated in Wind Tunnel Facilities subsection, it was not possible to match both $R e$ and $M$ simultaneously for WSU and F1 facilities.

Comparisons are thus shown at matched $R e$ with $M$ kept as close as possible and at matched $M$ while keeping $R e$ as close as possible. Figure 5a shows the lift and pitching moment, and Fig. 5b shows the drag curves. Generally, the data from WSU and F1 agreed well. The maximum lift coefficient for the WSU case was 1.01, which fell in between the two F1 cases $\left(C_{L, \max }=0.98\right.$ for $R e=1.6 \times 10^{6}$ and $C_{L, \max }=$ 1.04 for $R e=2.7 \times 10^{6}$ ). The two F1 cases showed slightly more gradual stall than the WSU case, but this was likely due to the data averaging (over $0.30^{\circ}$ angle of attack) that was done to reduce the noise in the F1 balance data. The stall angle of attack for the WSU case was $13.4^{\circ}$, while for $\mathrm{F} 1$ it was $12.6^{\circ}$ for $R e=1.6 \times 10^{6}$ and $13.1^{\circ}$ for $\mathrm{Re}=2.7 \times 10^{6}$. The lift values after stall agreed well between all three cases. The WSU and F1 lift curves should match exactly at the matched Mach number prior to stall. However, there was an offset of approximately $0.3^{\circ}$ in the angle of attack between the two (with the WSU data having the higher angle of attack). This indicated that there may be differences in the test section flow angularities in the WSU and F1 tunnels. The pitching moment curves generally showed good agreement between WSU and F1, with the break in the $C_{M}$ curve (associated with stalling wing) occurring at similar angles of attack. The WSU data exhibited more positive (or nose up) pitching moment at stall when compared to the $\mathrm{F} 1$ data at $R e=1.6$ million. This may have been due to the Mach number not being matched exactly. The drag curves show some discrepancies between WSU and F1 data. The F1 drag at $R e=1.6 \times 10^{6}$ and $M=0.09$ is higher than at $R e=2.7 \times 10^{6}$ and $M=0.18$ as expected due to $R e$ effects. It will be shown later in this paper that for the clean wing, the minimum drag values decreased with increasing $R e$ until $R e=4 \times 10^{6}$, after which it increased with increasing $R e$. There was no $M$ effect on drag values. However, the WSU drag was higher than the F1 drag even at matched $R e$. The reason for this mismatch was not clear but could have been partly due to the measurement uncertainties in the F1 data (operating at the very low end of the $q_{\infty}$ range). The minimum drag coefficient $\left(C_{D, \min }\right)$ values for the clean and iced configurations are shown in Table 8 . For the clean wing, there was a 9 drag count difference between the WSU and F1 $C_{D, \min }$ data at $R e=1.6 \times 10^{6}$. The iced configuration showed an average of 11 drag count difference in $C_{D, \min }$, with a standard deviation of $3.6 \mathrm{drag}$ counts. These differences in the $C_{D, \min }$ values are within the stated experimental uncertainties of both WSU and F1 tunnels, as shown in Tables 4 and 5 . 


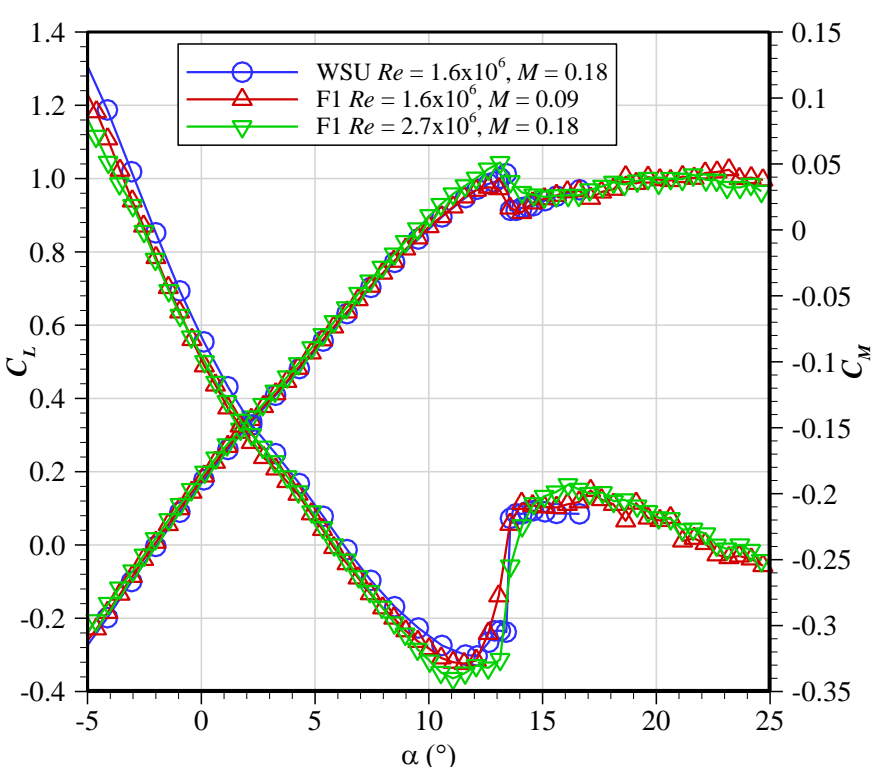

a) Lift and Pitching Moment

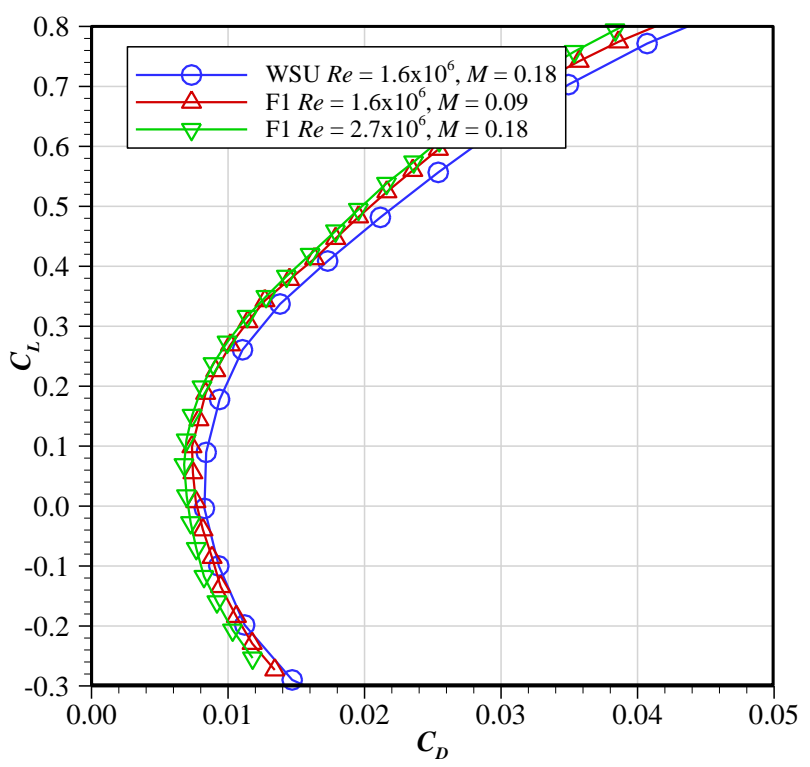

b) Drag

Figure 5. Clean wing performance comparison.
Table 8. Minimum drag coefficient comparison with various artificial ice shape configurations.

\begin{tabular}{|c|c|c|c|}
\hline Ice Shape & $\begin{array}{c}\text { WSU } \\
R e=1.6 \times 10^{6} \\
M=0.18\end{array}$ & $\begin{array}{c}\text { F1 } \\
R e=1.6 \times 10^{6} \\
M=0.09\end{array}$ & $\begin{array}{c}\text { F1 } \\
R e=2.7 \times 10^{6} \\
M=0.18\end{array}$ \\
\hline Clean & 0.0083 & 0.0074 & 0.0068 \\
\hline $\begin{array}{l}\text { Max Scallop 3D } \\
\text { Smooth } \\
\text { w/Hemispheres }\end{array}$ & 0.0172 & 0.0163 & 0.0159 \\
\hline $\begin{array}{c}\text { Max Scallop LEWICE } \\
\text { IFB w/grit }\end{array}$ & 0.0153 & 0.0142 & 0.0138 \\
\hline $\begin{array}{l}\text { Max Scallop LEWICE } \\
\text { IRT w/grit }\end{array}$ & 0.0161 & 0.0145 & 0.0139 \\
\hline $\begin{array}{l}\text { Max Scallop Artif. } \\
\text { Scallop Small Gap }\end{array}$ & 0.0187 & 0.0176 & 0.0169 \\
\hline $\begin{array}{l}\text { Max Scallop Artif. } \\
\text { Scallop Medium Gap }\end{array}$ & 0.0168 & 0.0160 & 0.0154 \\
\hline WB33 3D Smooth & 0.0169 & 0.0151 & 0.0152 \\
\hline $\begin{array}{l}\text { WB33 3D Smooth } \\
\text { w/grit }\end{array}$ & 0.0188 & 0.0176 & 0.0170 \\
\hline $\begin{array}{l}\text { WB33 LEWICE IFB } \\
\text { w/grit }\end{array}$ & 0.0153 & 0.0140 & 0.0136 \\
\hline WB33 Simple Horn & 0.0109 & 0.0103 & 0.0104 \\
\hline $\begin{array}{l}\text { WB33 Simple Horn } \\
\text { w/grit }\end{array}$ & 0.0134 & 0.0124 & 0.0116 \\
\hline
\end{tabular}

\section{Iced Configurations}

\section{Max Scallop 3D Smooth with Hemispheres}

Figure 6 shows the lift, pitching moment and drag curves for the Max Scallop 3D Smooth ice shape with hemispheres built into the surface (shown in Fig. 4b). It shows very good comparisons between WSU and $\mathrm{F} 1$ data. Both the lift and pitching moment curves compared very well between the WSU and F1 data (Fig. 6a). All of the cases show the lift curve becoming non-linear at $\alpha=7^{\circ}$, at the start of the stalling process. This was also indicated by the break in the pitching moment curve that also occurred at $\alpha=7^{\circ}$. The lift and pitching moment also compared very well at $\alpha$ above $7^{\circ}$ indicating that the stall progression in the WSU and the F1 data matched very well.

The lift and pitching moment curves show the same $0.3^{\circ}$ offset in $\alpha$ between WSU and F1 data that was shown in the clean data. The drag data (Fig. 6b) showed good comparison between the WSU and F1 except for the 9 drag count difference in the minimum drag values at matched $R e$. 


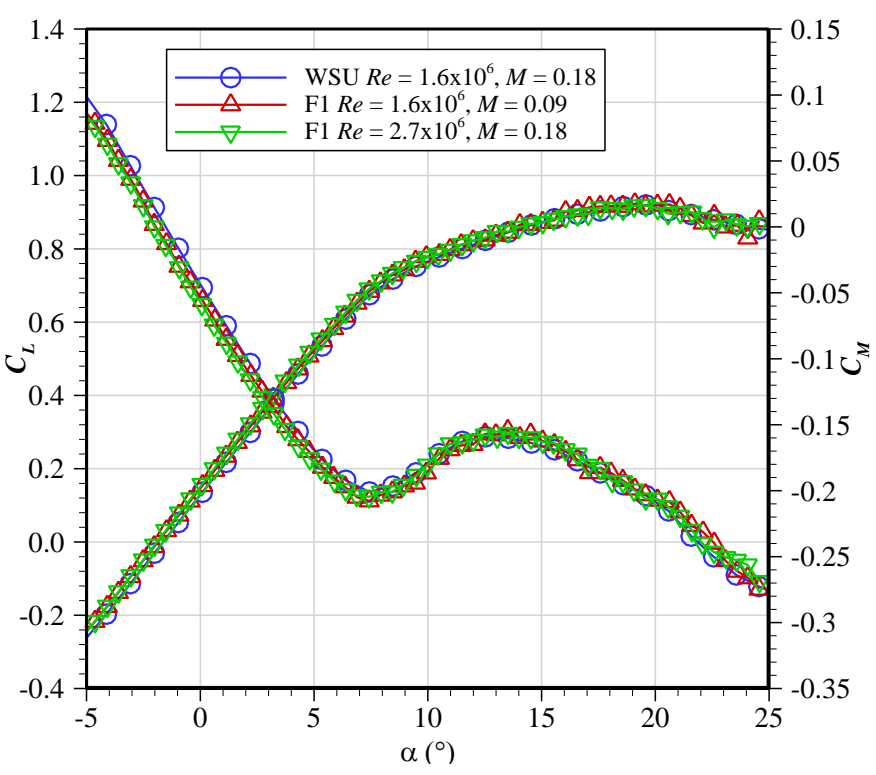

a) Lift and Pitching Moment

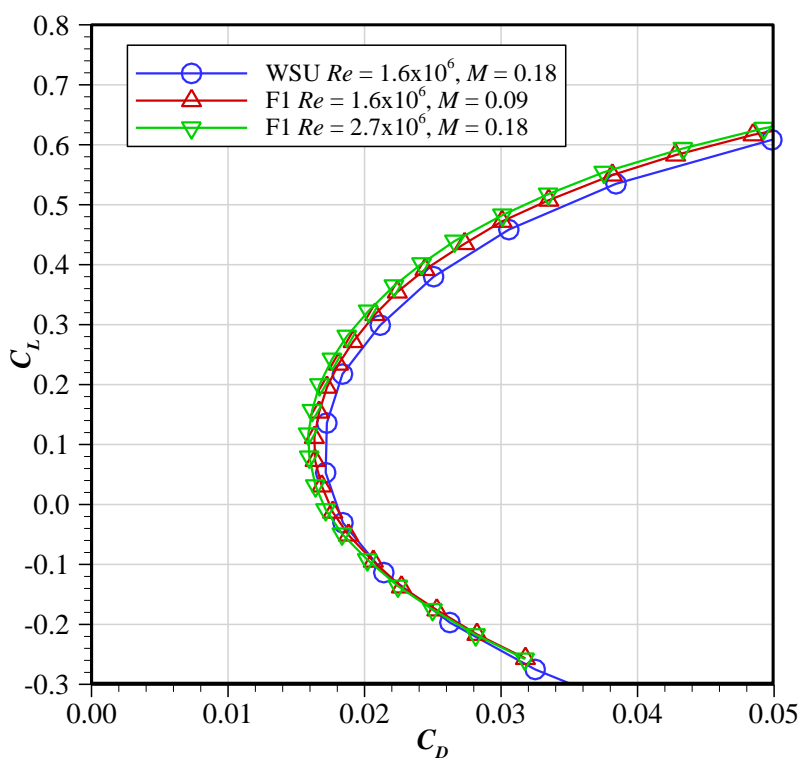

b) Drag

Figure 6. Performance comparison with Max Scallop 3D Smooth ice shape with hemispherical roughness.

\section{Max Scallop LEWICE IFB with Grit}

Figure 7 shows the lift and pitching moment curves for the WSU and F1 data with the Max Scallop LEWICE IFB shape with the grit attached (Fig. 4c). Both the lift and pitching moment curves compared very well between the WSU and F1 data at matched $R e$ and $M$. The location and shape of the breaks in the lift and pitching moment curves $\left(\alpha=8^{\circ}\right)$ matched very well, as well as the lift and pitching moment in the non-linear region $\left(\alpha>8^{\circ}\right)$. The drag data compared well as well except for the $11 \mathrm{drag}$ count difference at matched Re shown in Table 8. The drag curves are not shown for this and subsequent ice shapes because they are identical in nature to what was shown in Fig. 6 and do not offer any additional insight into any discrepancies between the WSU and F1 data.

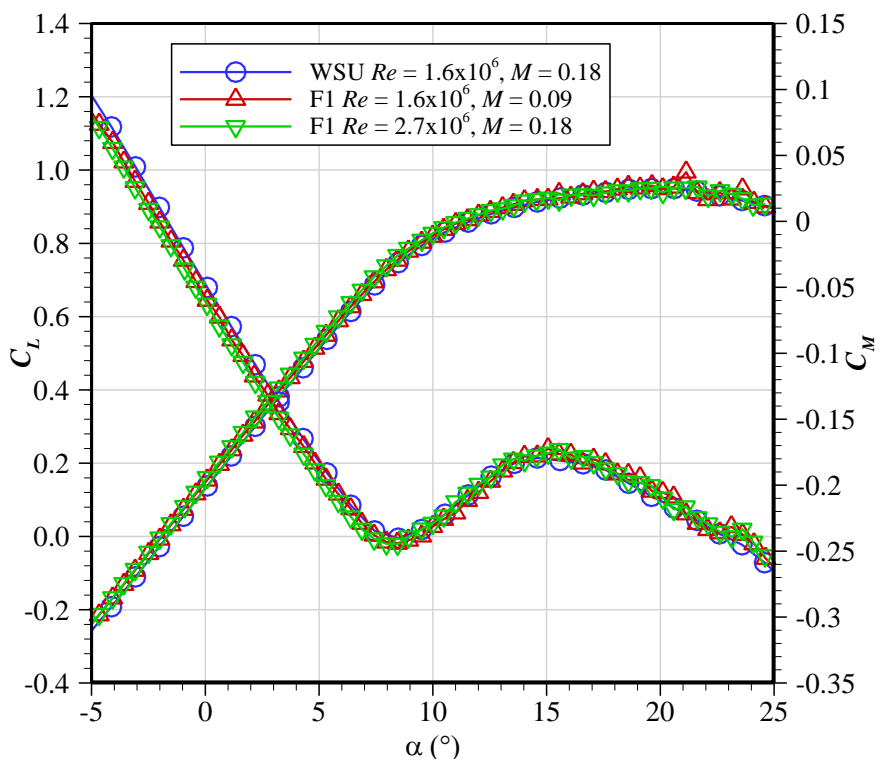

Figure 7. Performance comparison with Max Scallop LEWICE IFB with grit.

\section{Max Scallop LEWICE IRT with Grit}

Figure 8 shows the lift and pitching moment curves for the Max Scallop LEWICE IRT shape with the grit attached (Fig. 4d). Both the lift and pitching moment curves compared very well between the WSU and F1 data at matched Reynolds and Mach numbers. The lift and pitching moment curves matched very well in the non-linear regions $\left(\alpha>8^{\circ}\right.$, where there was a break in the pitching moment), indicating that the stall progression matched very well. Table 8 shows that there was a 16 drag count difference between WSU and F1 at matched $R e$.

Page 8 of 19 


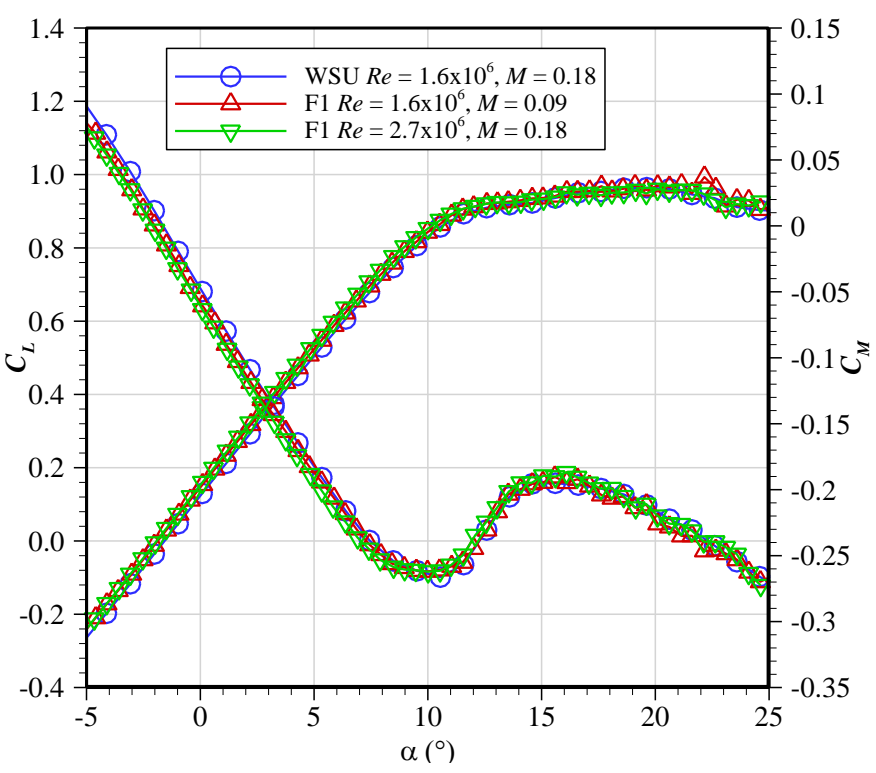

Figure 8. Performance comparison with Max Scallop LEWICE IRT with grit.

\section{Max Scallop Artificial Scallop with Small Gap}

Figure 9 shows the lift and pitching moment curves for the Max Scallop Artificial Scallop shape with small gap spacing (Fig. 4e). The lift curves compared very well between the WSU and F1 data at matched $\operatorname{Re}$ and $M$. The pitching moment curves compared very well up to $\alpha=8^{\circ}$. The WSU data had slightly flatter curve between $\alpha=8^{\circ}$ and $15^{\circ}$, when compared to the F1 data, indicating that the stall progression for the WSU data was slightly different than the F1 data. A possible explanation for this difference was that the gap spacing on the WSU model at the wing tip was so small ( $\sim 0.025$ ”) that the $3 \mathrm{D}$ printing method was not able to reproduce the gaps near the tip of the wing, and was more solid in nature, when compared to the ice shape on the F1 model. This may have led to slightly different flow separation characteristics near the tip which affected the pitching moment. This was only seen in the pitching moment and not in lift because the pitching moment is more sensitive to slight variations in the wing boundary layer state. The drag data compared well except for the 11 drag count difference between WSU and F1 data.

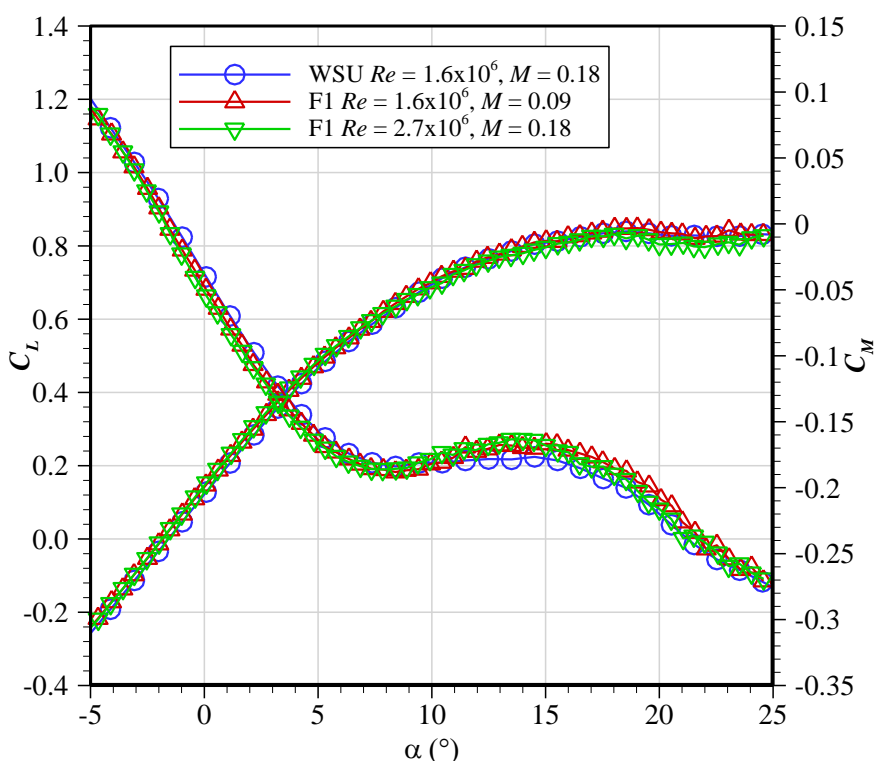

Figure 9. Performance comparison with Max Scallop Artificial Scallop with small gap spacing.

\section{Max Scallop Artificial Scallop with Medium Gap}

Figure 10 shows the lift and pitching moment curves for the Max Scallop Artificial Scallop shape with medium gap spacing (Fig. 4f). The lift data compared very well between the WSU and F1 data at matched $R e$ and $M$. The pitching moment curve compared better than the shape with the small gap spacing (Fig. 9). At this intermediate gap spacing, there were no issues with the 3D printing of the gaps in the WSU model. Table 8 shows 8 drag count difference between the WSU and F1 data at matched Reynolds number.

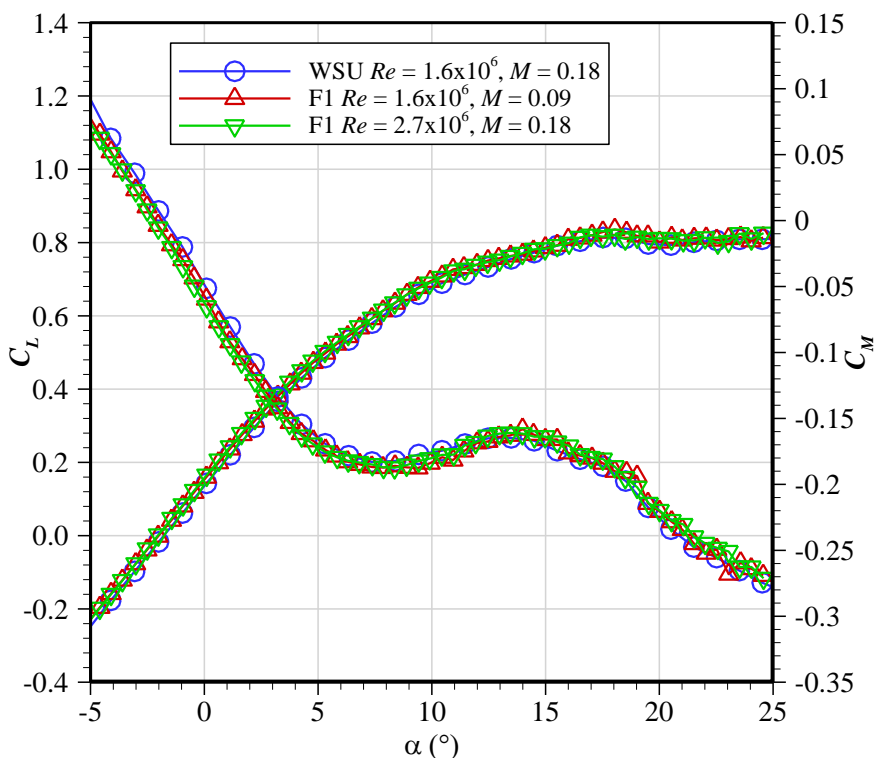

Figure 10. Performance comparison with Max Scallop Artificial Scallop with medium gap spacing. 


\section{WB33 3D Smooth}

Figure 11 shows the comparison of the WB33 3D Smooth ice shape (Fig. 4g) tested at WSU and F1 wind tunnels. The lift and pitching moment data compared very well between the two facilities at matched Reynolds number of 1.6 million. There were some differences between the WSU and F1 data at matched Mach number of 0.18 , especially in the pitching moment at $\alpha=7^{\circ}$ to $12^{\circ}$. This indicated that there were some Reynolds number effects with this ice shape. This was consistent with the results presented in Broeren, et al. [11] that showed "3D Smooth"-type ice shapes can exhibit small Reynolds number effects that can be reduced or eliminated with application of roughness grits on the ice shapes. The minimum drag values are shown in Table 8 . The 18 drag count discrepancy between the WSU and F1 values at $R e=1.6 \times 10^{6}$ was larger than with other ice shape configurations, but this may have been due to erroneous F1 data (with large uncertainties at this dynamic pressure).

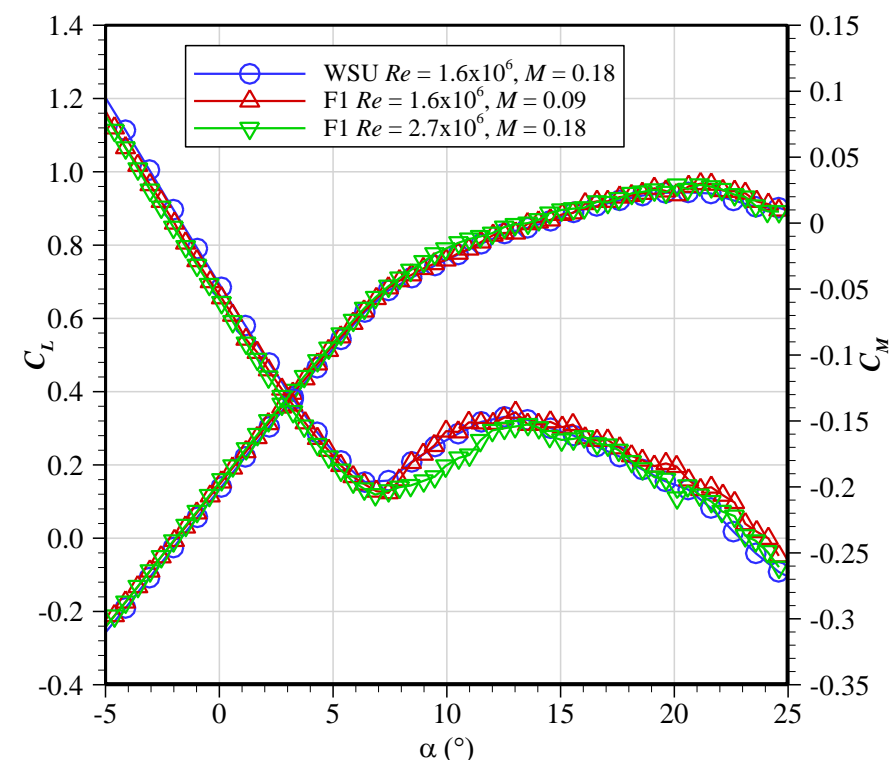

Figure 11. Performance comparison with WB33 3D Smooth ice shape.

\section{WB33 3D Smooth with Grit}

Figure 12 shows the comparison of the WB33 3D Smooth ice shape with the roughness grit applied (Fig. 4g). There was a very good agreement in the lift and pitching moment data between the WSU and F1 data at both matched Reynolds and Mach number. The presence of the grit eliminated the slight Reynolds number effect present in the pitching moment data observed in Fig. 11. The drag data shown in Table 8 were consistent with other ice-shape configurations.

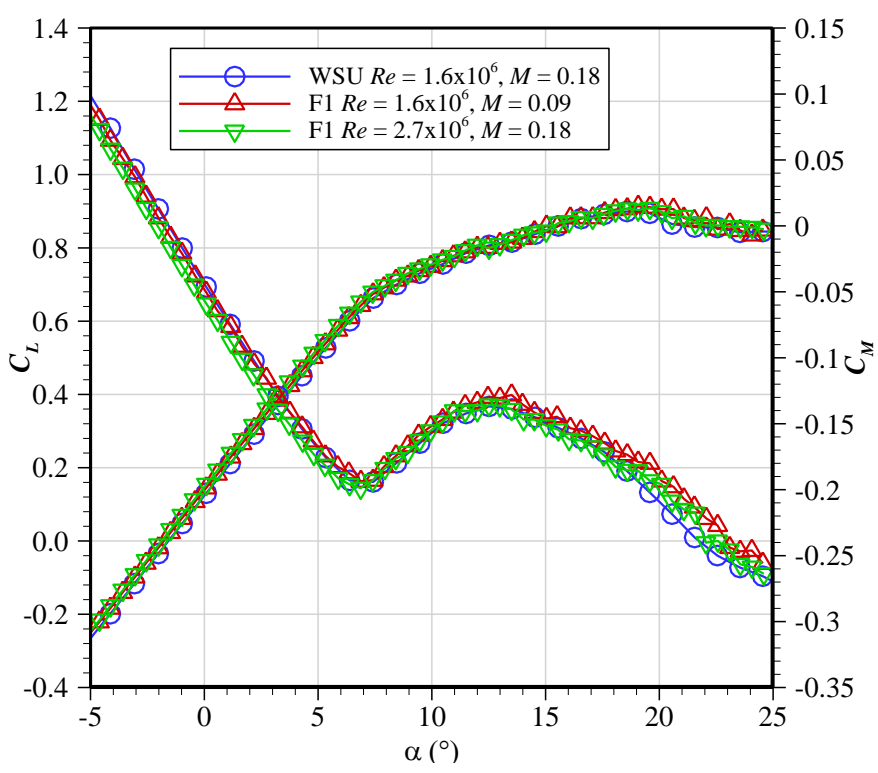

Figure 12. Performance comparison with WB33 3D Smooth ice shape with grit.

\section{WB33 LEWICE IFB with Grit}

Figure 13 shows the lift and pitching moment curves for WB33 Appendix C LEWICE IFB shape with the grit attached (Fig. 4h). Both the lift and pitching moment curves compared very well between the WSU and F1 data at matched $R e$ and $M$. The location and shape of the breaks in the lift and pitching moment curves ( $\alpha=$ $7^{\circ}$ ) matched very well, as well as the lift and pitching moment in the non-linear region up to stall. The minimum drag values are shown in Table 8.

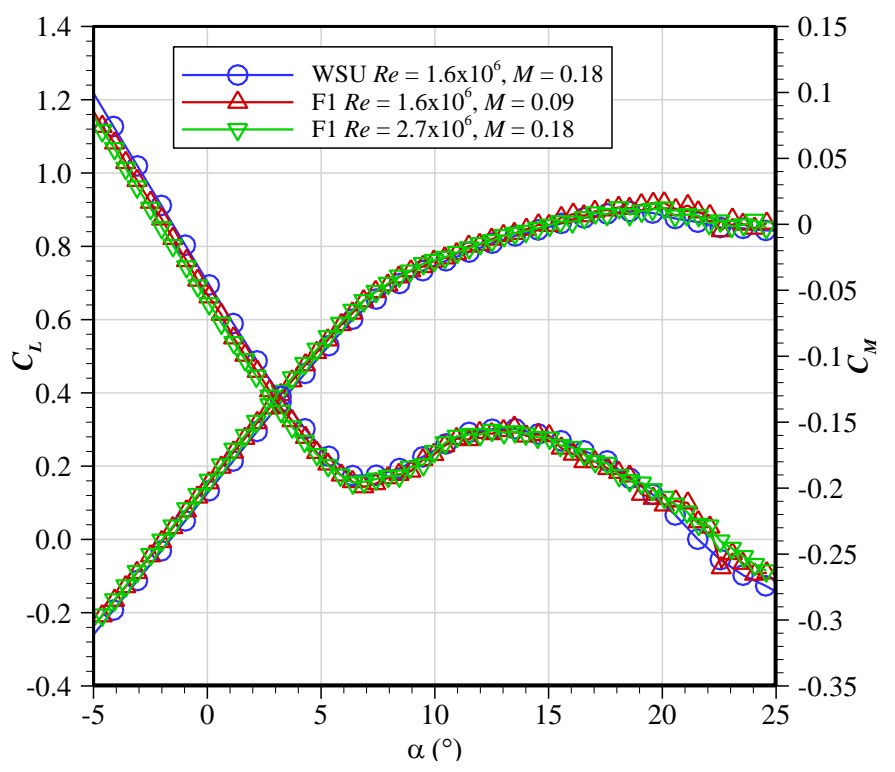

Figure 13. Performance comparison with WB33 LEWICE IFB ice shape with grit. 


\section{WB33 Simple Horn}

Figure 14 shows the lift and pitching moment curves for the WB33 simple horn shape (Fig. 4i). This shape did not have any roughness grit applied to the surface. Both the lift and pitching moment curves compared very well between the WSU and F1 data in the linear region, and the start of the non-linear region $\left(\alpha=6^{\circ}\right)$ compared very well. However, there were some differences in the non-linear regions (above $\alpha=6^{\circ}$ ). The WSU data had lift values that were lower than the F1 data at both matched $R e$ and $M$. The pitching moment curves from the WSU data compared better with the F1 data at the matched $R e$ of 1.6 million than at the matched $M$ of 0.18 . There appeared to be some $R e$ effect in the F1 data, similar to what was observed for the WB33 Appendix C 3D Smooth ice shape without the grit, shown in Fig. 11. However, unlike that shape (where the WSU data agreed with the F1 data very well at matched $R e$ ), the WSU data and the F1 data did not agree as well at matched $R e$. Table 8 shows the minimum drag values for this ice shape.

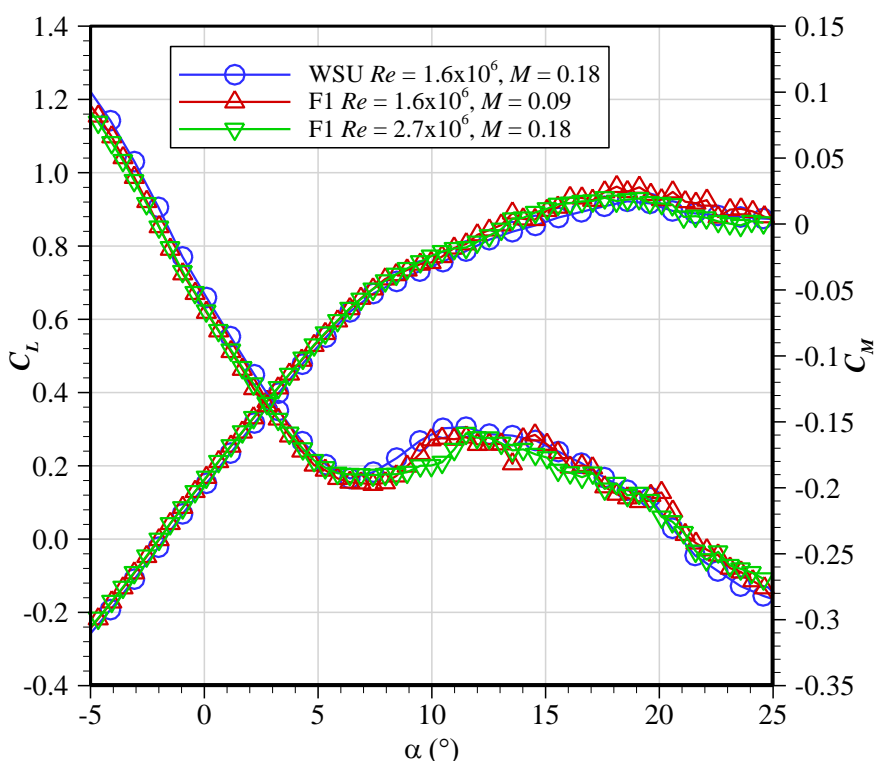

Figure 14. Performance comparison with WB33 Simple Horn ice shape.

\section{WB33 Simple Horn with Grit}

Figure 15 shows the lift and pitching moment curves for the WB33 Appendix $\mathrm{C}$ simple horn shape with roughness grits (Fig. 4i). Both the lift and pitching moment curves compared very well between the WSU and F1 data at matched $R e$ and $M$, better than the case without the grit (Fig. 14). These results are consistent with the data from other locally 2D ice shapes (i.e. "3D Smooth") in that grits were required to reduce $R e$ and $M$ effects and the differences from testing at different scale and facilities. The drag data shown in Table 8 were consistent with the results from tests with other ice shapes.

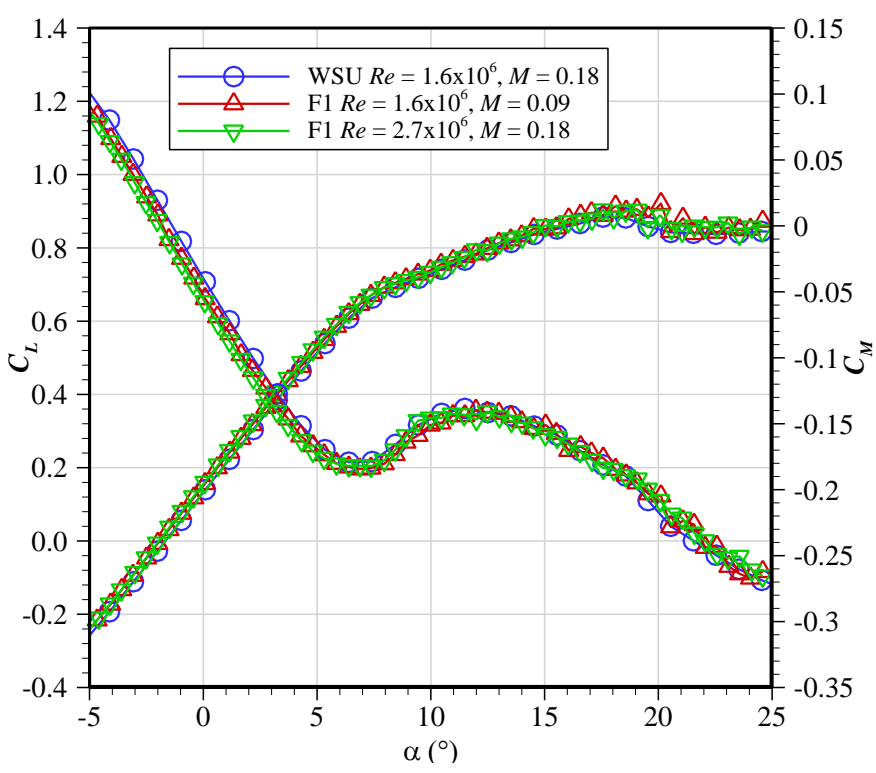

Figure 15. Performance comparison with WB33 Simple Horn ice shape with grit.

\section{Performance Parameters}

Broeren, et al. [11] presented several performance parameters to quantify the effects of ice shape geometry on swept wing performance. Maximum lift coefficient, $C_{L, \max }$, has traditionally been used as the most important and easily identifiable performance parameter. Stall angle of attack, $\alpha_{\text {stall }}$, is traditionally defined as the angle of attack at which the $C_{L, \max }$ occurs. For the clean wing tested in $\mathrm{F} 1$ at $R e=1.6 \times 10^{6}$ and $M=0.09$ (Fig. 5), the $C_{L, \max }=0.98$ with $\alpha_{\text {stall }}=12.6^{\circ}$. For Maximum Scallop 3D Smooth ice shape with hemispherical roughness tested in F1 at $R e=1.6 \times 10^{6}$ and $M=0.09$ (Fig. 6), $C_{L, \max }=0.92$ with $\alpha_{\text {stall }}=20.6^{\circ}$. The results from the WSU and $\mathrm{F} 1$ test showed that the stall angles for iced configurations were typically higher than for the clean wing, which was quite different from what was observed in prior research on straight wings or airfoils with large leading edge ice shapes where iced wings stalled at lower angles of attack. Figure 6 shows that for the Maximum Scallop 3D Smooth ice shape with hemispherical roughness configuration, the wing stall process began at a much lower angle of attack $\left(\alpha=7^{\circ}\right)$, when compared to the clean wing, as indicated by an abrupt reduction in the lift curve slope and a large change in the slope of the pitching moment. Flow visualization from the mini-tuft images and surface oil flow showed that the break in the pitching moment coincides with the start of large-scale flow separation [11]. The flow was separated over most of the wing well before the traditionally defined $C_{L, \max }$ and $\alpha_{\text {stall }}$ was reached, with potentially large undesirable controllability issues. Because of this, the use of maximum lift coefficient and stalling angle may not necessarily be the best indicator of the stall progression on the swept, CRM65 wing with artificial ice shapes. This led to the identification of an additional performance metric that was associated with the change in the pitching-moment coefficient based on the work in 1957 by Furlong and McHugh [26].

Furlong and McHugh identified a performance-based parameter called "usable" lift based on their review of previous work on low $R e$ swept wings. For convenience, the authors assumed that the quarterchord MAC location was coincident with the airplane center of gravity. Therefore, the longitudinal stability could be referred to as either stable or unstable depending on the slope of the pitching- 
moment curve with respect to angle of attack. The change from a negative slope to a positive slope occurs at the first local minimum in the $C_{M}$ vs $\alpha$ curve, and stall control would be required beyond this angle of attack. The lift coefficient at this angle of attack was described as the usable lift coefficient, or $C_{L \text {,use }}$. This interpretation of usable lift implies that a certain amount of flow separation on the wing has crossed some threshold such that this value of the usable lift coefficient may be more significant than the absolute value of the maximum lift coefficient. This interpretation of usable lift is applicable to the iced-wing aerodynamic effects observed within the present data set.

Two drag-based performance parameters were also presented by Broeren, et al. [11], based on report by Lynch and Khodadoust [27]. The first was the minimum drag coefficient $\left(C_{D, \min }\right)$ which was the change in the profile drag since the induced drag would be nearly zero at these angles of attack. The other parameter was based on drag at flight speed $30 \%$ above 1 -g stall speed (or $V=1.3 V_{\text {stall }}$ ) for the clean configuration. This speed is a typical reference speed in aviation. For the CRM65 wing used in this study, this was represented by drag at $C_{L}=0.6$ or $C_{D, 0.6}$. A more detail description of these performance parameters can be found in Broeren, et al. [11]

Broeren, et al. [11] and Lee, et al [17] showed that there was no Reynolds and Mach number effects on the lift-based performance parameters with "High Fidelity" versions of highly 3D ice shapes, such as Max Scallop and WB33 ice shapes shown in Fig. 3. This allowed lift-based performance parameters from low Re tests at WSU to be applied to high $R e$ without any corrections. However, slight $R e$ effects were observed in two "3D Smooth" ice shapes (one of which was Max Scallop) that were tested. These $R e$ effects were eliminated when they were tested with roughness grits. This indicated that grits are required when testing "3D Smooth"-style ice shapes in order to fully eliminate $R e$ effects. Additionally, small $R e$ effects were observed in drag-based performance parameters for all iced configurations. In the current report, additional data (that were not available for previous reports) are presented for 3D smooth shapes based on WB33, including simple horn shape that share similar morphology. These shapes were tested with and without grits to determine if they followed the same trends reported in Broeren, et al. [11] and Lee, et al. [17]

\section{Clean Wing}

The comparison of the performance parameters between the WSU and F1 data for the clean wing is shown in Fig. 16. Figure 16a shows the comparison of the maximum lift coefficient vs. Reynolds number. The F1 data shows $C_{L, \max }$ at fixed Mach numbers of $0.09,0.18$, and 0.23 . The WSU curve is not at fixed Mach number since the Reynolds number cannot be independently varied from the Mach number since it is an atmospheric wind tunnel. The F1 data clearly show both Reynolds number and Mach number effects. The $C_{L, \max }$ increased with increasing Reynolds number, while it decreased with increasing Mach number. Observing this effect is only possible in wind tunnel facilities such as F1 where $R e$ and $M$ can be independently varied. These trends are impossible to identify in the WSU data where an increase in $R e$ also resulted in the increase in $M$. However, the $C_{L, \max }$ value from the WSU data at $R e=1.6 \times 10^{6}$ and $M$ $=0.18$ (1.01) compared reasonably well to F1 value at $R e=1.6 \times 10^{6}$ and $M=0.09(0.98)$. Also, the $C_{L, \max }$ value from WSU at $R e=$ $1.6 \times 10^{6}$ and $M=0.18(1.01)$ was also reasonably close to the F1 value at $R e=2.7 \times 10^{6}$ and $M=0.18$ (1.04). Figure $16 \mathrm{~b}$ shows the comparison of the usable lift coefficient, $C_{L, u s e}$, as defined by Furlong and McHugh [26]. The F1 data clearly show Reynolds number

Page 12 of 19 effects in the usable lift values, just like with the maximum lift. However, there was no Mach number effect between $M=0.09$ and 0.18 . The WSU data agreed well with the F1 data at $R e=1.6 \times 10^{6}$ and near $R e=2.4 \times 10^{6}$.

Figure $16 \mathrm{c}$ shows the comparison of the minimum drag values. The F1 data shows that there was no Mach number effect on the $C_{D \text {, min }}$ value. The minimum drag values decreased with increasing Reynolds number from $1.6 \times 10^{6}$ to $4 \times 10^{6}$ and then started to increase with increasing Reynolds number. The WSU data followed the trends observed in the F1 data, except for the offset of approximately 0.001 (or 10 drag counts) that was shown in Fig. 5. Figure 16d shows the comparison of the drag coefficient at $C_{L}=0.6$ (or $C_{D, 0.6}$ ). The $C_{D, 0.6}$ values also exhibited no Mach number effect. However, the Reynolds number effects were slightly different in that the $C_{D, 0.6}$ values decreased with increasing Reynolds number in all $R e$ range. The WSU data followed the trends shown in the F1 data, although with an offset of approximately 0.002 (or 20 drag counts).

The performance parameters from the clean wing showed that for lift values, a pressurized tunnel is required to study the independent effects of $R e$ and $M$ on clean wing. However, the WSU data did match the F1 data at matched Reynolds number and when Mach numbers were reasonably close. For drag values, a pressurized tunnel was not required since there was no $M$ effect in drag. The low $R e$ results from WSU can be extended into the high $R e$ results from F1 (at least over the range of $M$ and $R e$ shown) once the offset in the drag values between the two facilities is accounted for.

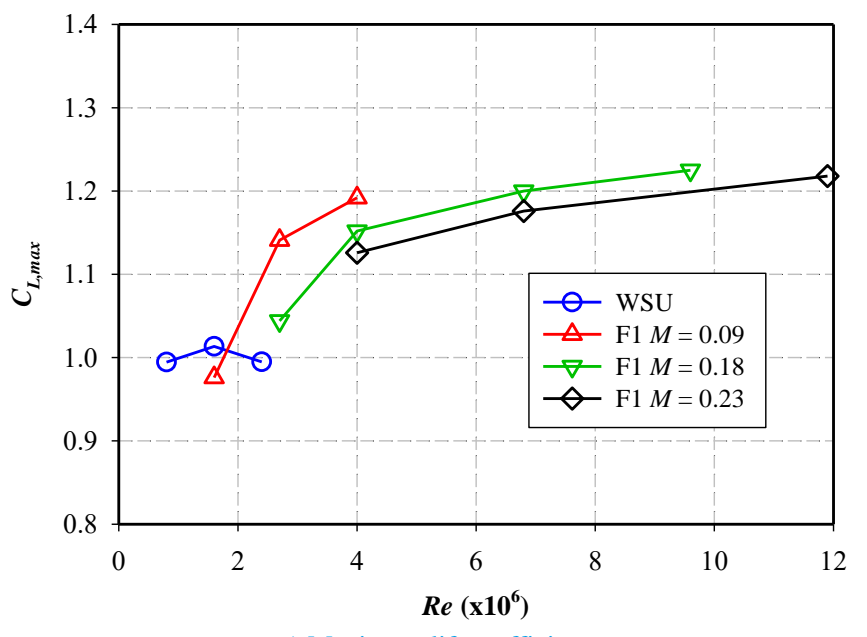

a) Maximum lift coefficient. 


\section{WB33 3D Smooth}

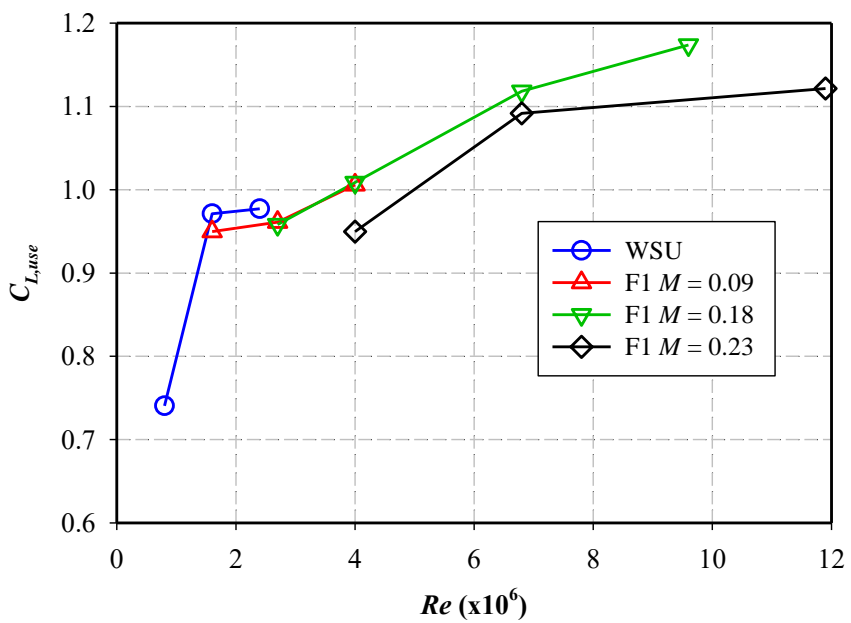

b) Usable lift coefficient.

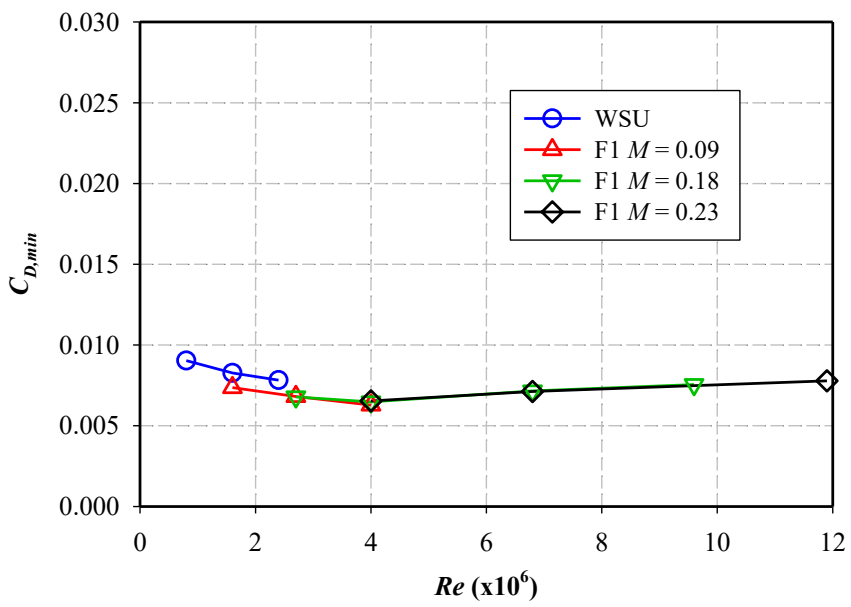

c) Minimum drag coefficient.

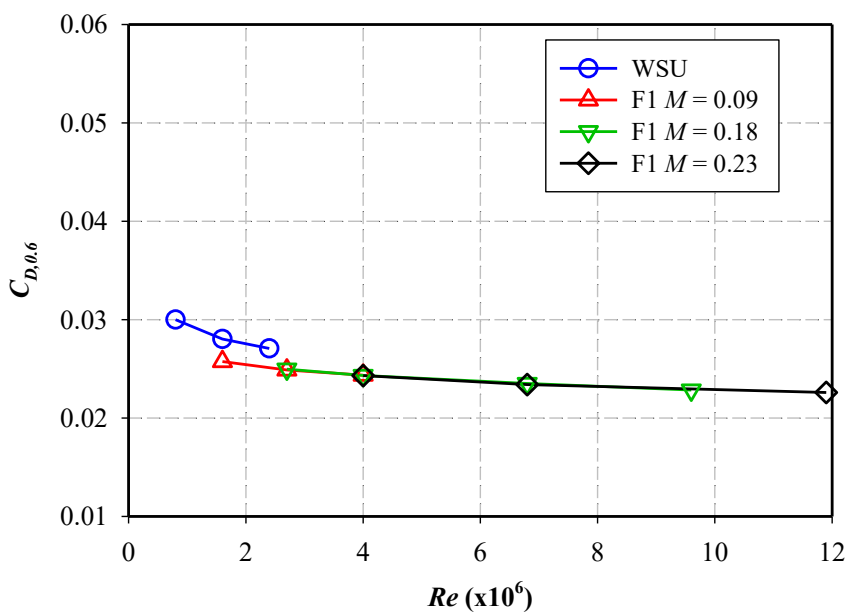

d) Drag coefficient at $C_{L}=0.6$.

Figure 16. Performance parameter comparisons with clean wing.
Figure 17 shows the comparison of the performance parameters with the WB33 3D Smooth ice shape. Figure 17a shows the comparison of the maximum lift coefficient. The figure shows that there were slight Reynolds and Mach number effects in the F1 data. At $M=$ 0.09 , the $C_{L, \max }$ values increase slightly from $R e=1.6 \times 10^{6}$ to $4 \times 10^{6}$. At $M=0.18$ and 0.23 , the $C_{L, \max }$ values decreased slightly with increasing $R e$. However, these variations were significantly less than those observed for the clean wing shown in Fig. 16a. The WSU and F1 data agreed well at matched Reynolds number of $1.6 \times 10^{6}(0.94$ for WSU and 0.97 for F1). Similar trends were observed in the $C_{L \text {,use }}$ plots shown in Fig. 17b. In the F1 data, there were slight variations in the $C_{L, u s e}$ values with $\operatorname{Re}$ and $M$. However, there was a larger difference in the $C_{L \text {,use }}$ value between WSU and F1 at $R e=1.6 \times 10^{6}$ (0.62 for WSU and 0.68 ). Figure $17 \mathrm{c}$ and $17 \mathrm{~d}$ show the comparisons of the drag-based performance parameters. There was no $M$ effect, and slight $R e$ effect (with decreasing drag values with increasing Reynolds number). The offset in the drag values between the WSU and F1 data are clearly present in the drag plots.

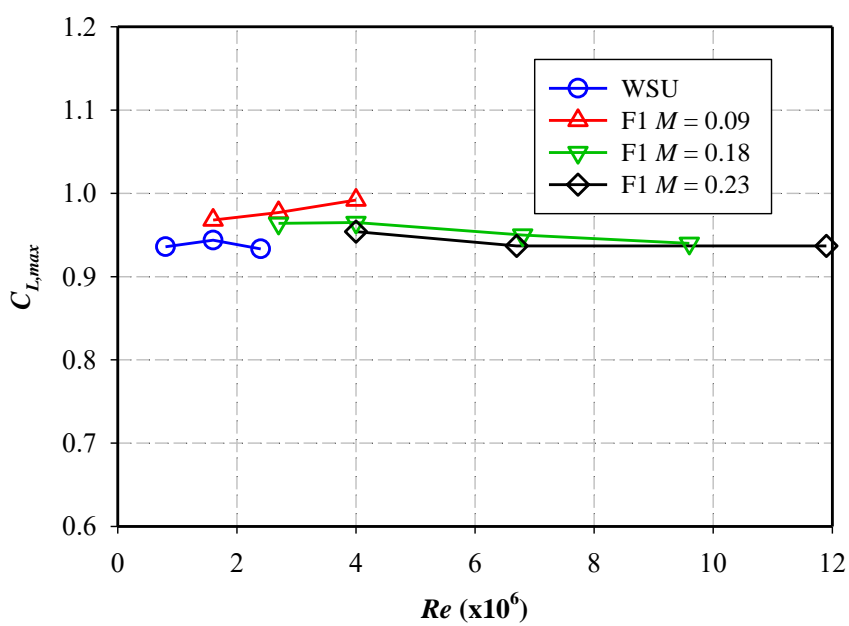

a) Maximum lift coefficient

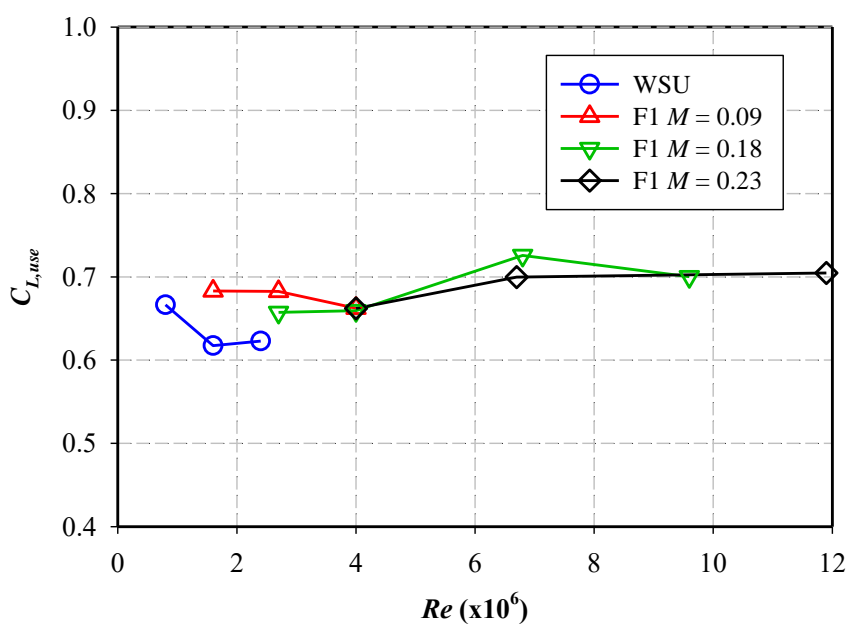

b) Usable lift coefficient.

Page 13 of 19 


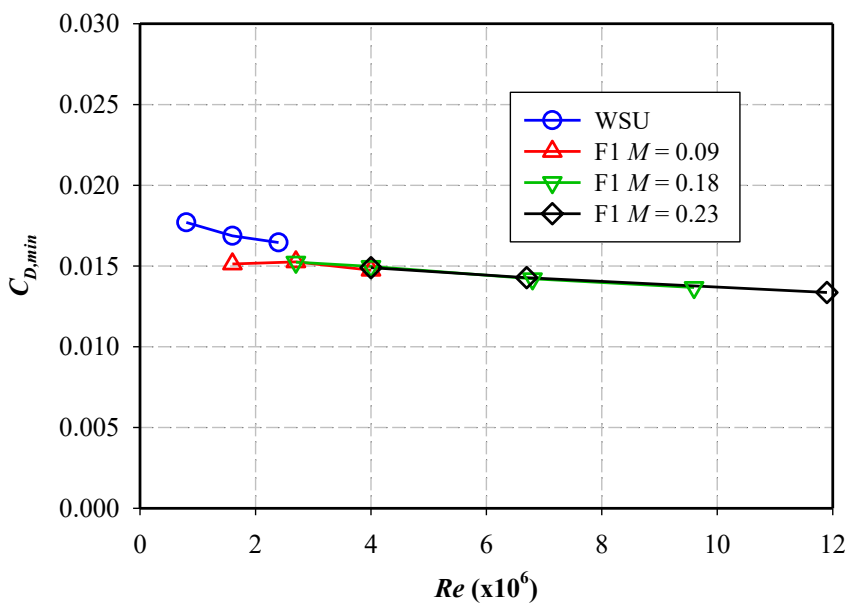

c) Minimum drag coefficient.

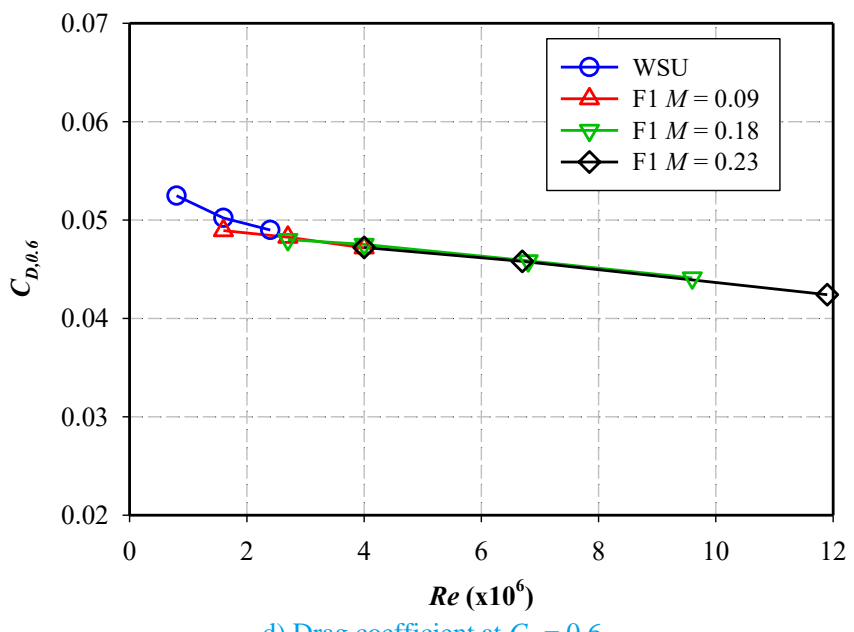

d) Drag coefficient at $C_{L}=0.6$.

Figure 17. Performance parameter comparisons with WB33 3D Smooth ice shape.

\section{WB33 3D Smooth with Grit}

Figure 18 shows the comparison of the WB33 Appendix C 3D Smooth ice shape with roughness grit. Figure 18a shows the comparison of the maximum lift coefficient. It shows that there was very little Reynolds number effect in the WSU and F1 data (except for the F1 data at $R e=1.6 \times 10^{6}$ and $M=0.09$ ). The WSU and F1 data agreed very well at matched Reynolds number of $1.6 \times 10^{6}(0.90$ for WSU and 0.91 for F1).

The comparison of $C_{L \text {,use }}$ is shown on Fig. 19b. There were almost no $R e$ or $M$ effects in the $C_{L, u s e}$ values, except for the WSU data at $R e$ $=2.4 \times 10^{6}$. This discrepancy in the $C_{L, \text { use }}$ value was due to the WSU data being acquired at every $1^{\circ}$ angle of attack. At $R e=2.4 \times 10^{6}$, $C_{M, \min }$ was measured at $\alpha=6^{\circ}$, with a corresponding $C_{L \text {,use }}$ value of 0.61 . However, the $C_{M, \min }$ likely occurred at $\alpha$ between $6^{\circ}$ and $7^{\circ}$, but there were no data acquired between these angles of attack. At $R e=0.8 \times 10^{6}$ and $1.6 \times 10^{6}, C_{M, \min }$ was measured at $\alpha=7^{\circ}$, but likely occurred between $6^{\circ}$ and $7^{\circ}$ as well. If $C_{M, \min }$ for $R e=2.4 \times 10^{6}$ was measured at $\alpha=7^{\circ}$, then the $C_{L, u s e}$ value would have been 0.67 and matched the other conditions better.

At matched Reynolds number of $1.6 \times 10^{6}$, the WSU and F1 data agreed very well. The addition of the roughness grit to this geometry reduced the $R e$ and $M$ effects on the lift-based performance parameters and resulted in better comparison between WSU and F1 data at matched Reynolds number. Because of this, the low Reynolds number results from the WSU could be applied to much higher Reynolds number without any correction to the data.

Figures $18 \mathrm{c}$ and $18 \mathrm{~d}$ show the comparisons of the drag-based performance parameters. The trends shown here are consistent with those from the WB33 3D Smooth shape without the grit (Figs. 17c and $17 \mathrm{~d}$ ). There was no $M$ effect, and slight $R e$ effects. There was also an offset in the drag between the WSU and F1 data.

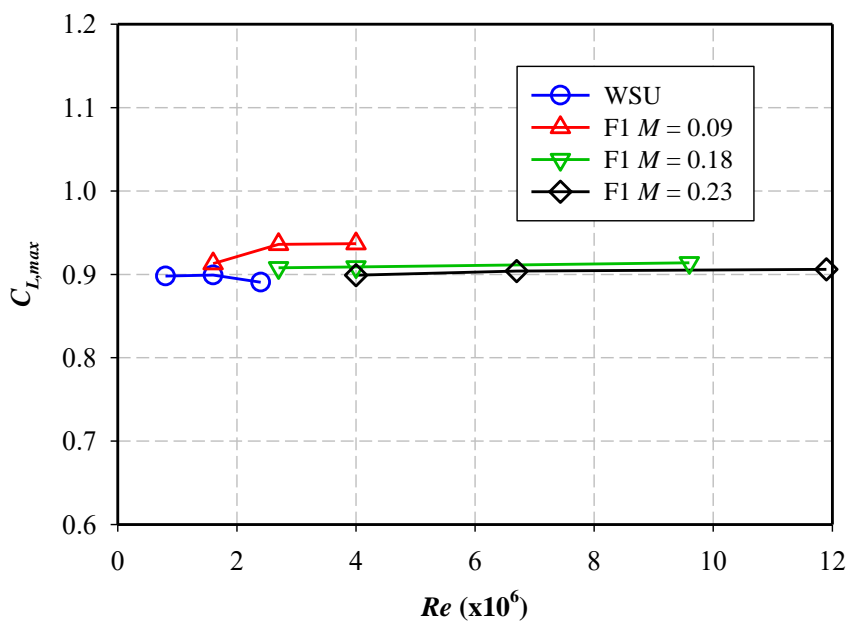

a) Maximum lift coefficient.

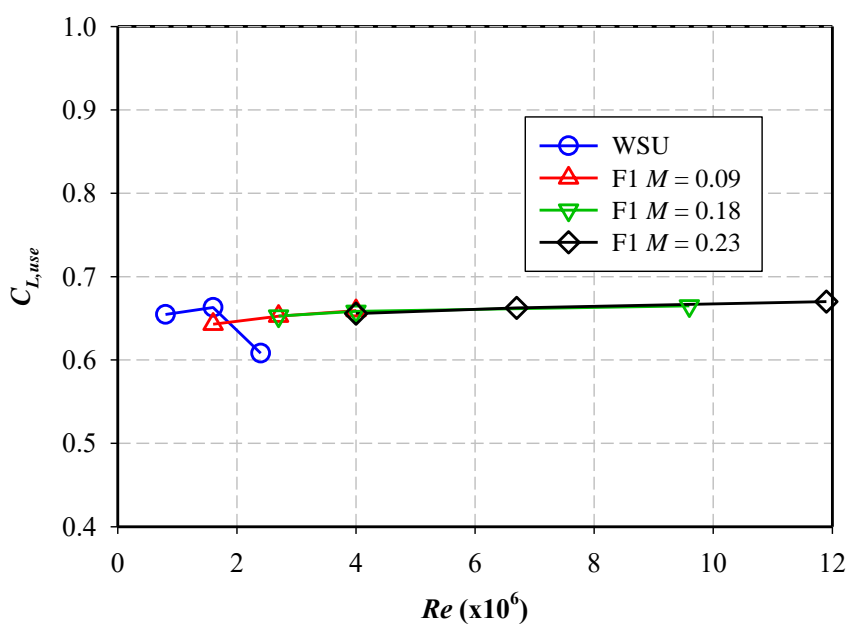

b) Usable lift coefficient. 


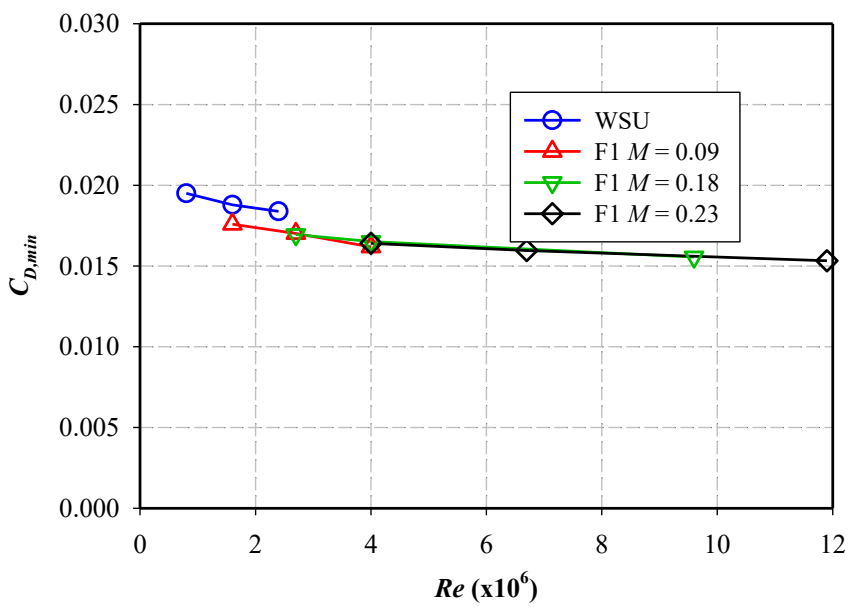

c) Minimum drag coefficient.

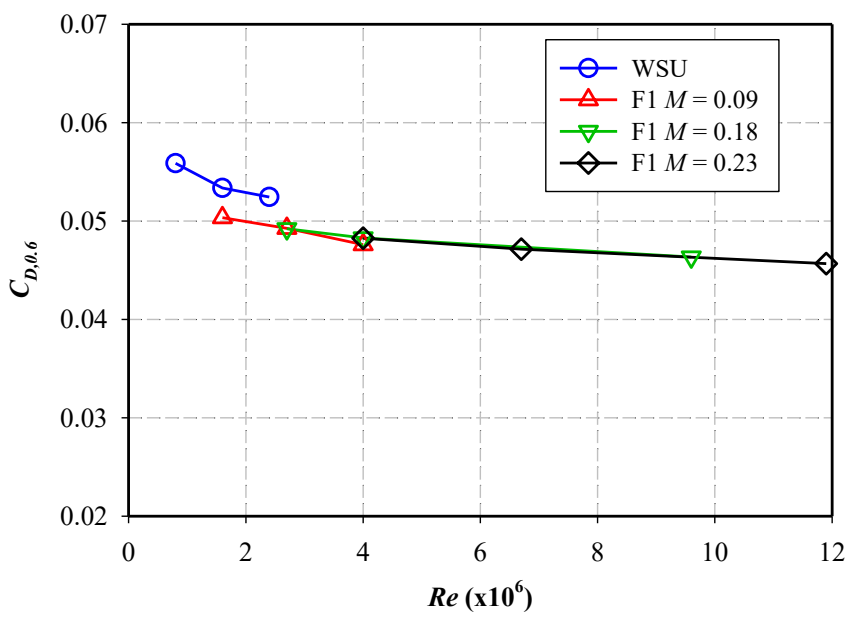

d) Drag coefficient at $C_{L}=0.6$.

Figure 18. Performance parameter comparisons with WB33 3D Smooth ice shape with grit.

\section{WB33 Simple Horn}

Figure 19 shows the comparison of the WB33 Simple Horn ice shape. The comparison of the maximum lift coefficient is shown in Fig. 19a. There was a slight Mach number effect in the $C_{L, \max }$ values, and there appears to be little to no Reynolds number effect. There was also a slight difference between the WSU and F1 data at matched $R e=$ $1.6 \times 10^{6}(0.92$ for WSU and 0.96 for F1). This may have been due to the Mach number effect since the WSU data was at $M=0.18$ while the $\mathrm{F} 1$ data was at $M=0.09$. Figure $20 \mathrm{~b}$ shows the comparison of the usable lift coefficient values. There were both $R e$ and $M$ effects on the F1 data. There was a larger difference in the $C_{L, \text { use }}$ values between the WSU and F1 data at $R e=1.6 \times 10^{6}(0.62$ for WSU and 0.68 for F1). Figure 19c and 19d show the comparisons of the dragbased performance parameters. The data shows no Mach number effects and a slight Reynolds number effect. The drag values increased with increasing Reynolds number for $R e<2.4 \times 10^{6}$. At $R e$ $>2.4 \times 10^{6}$, the drag values decreased with increasing Reynolds number.

Page 15 of 19

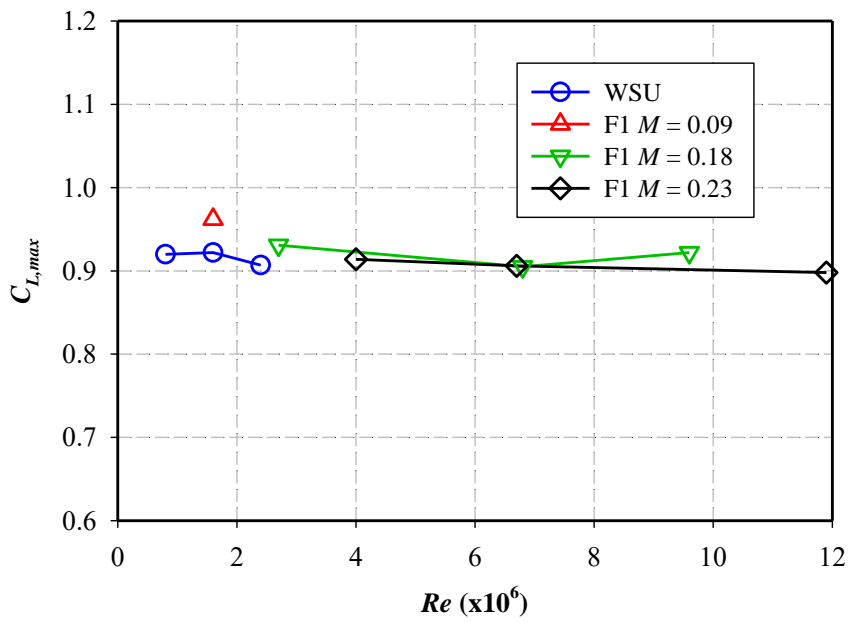

a) Maximum lift coefficient.

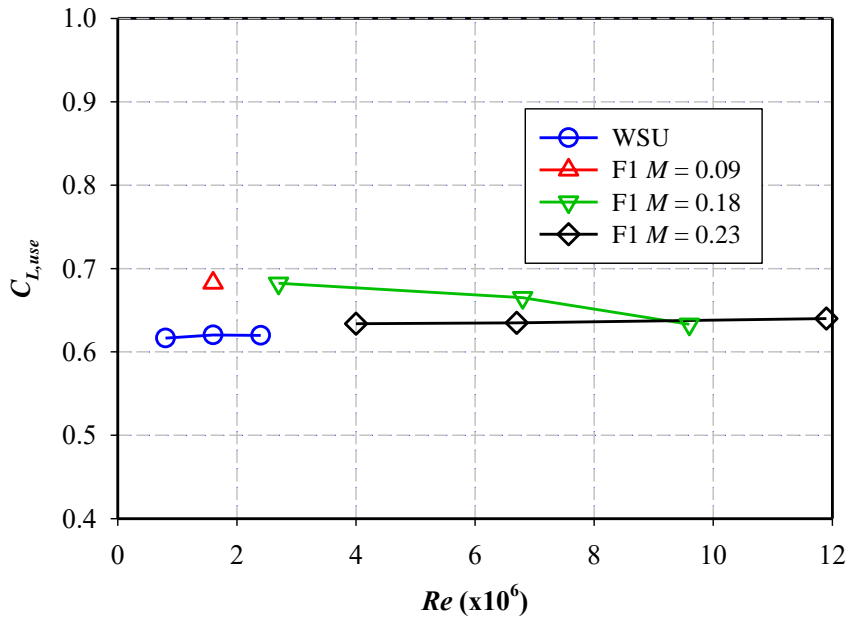

b) Usable lift coefficient.

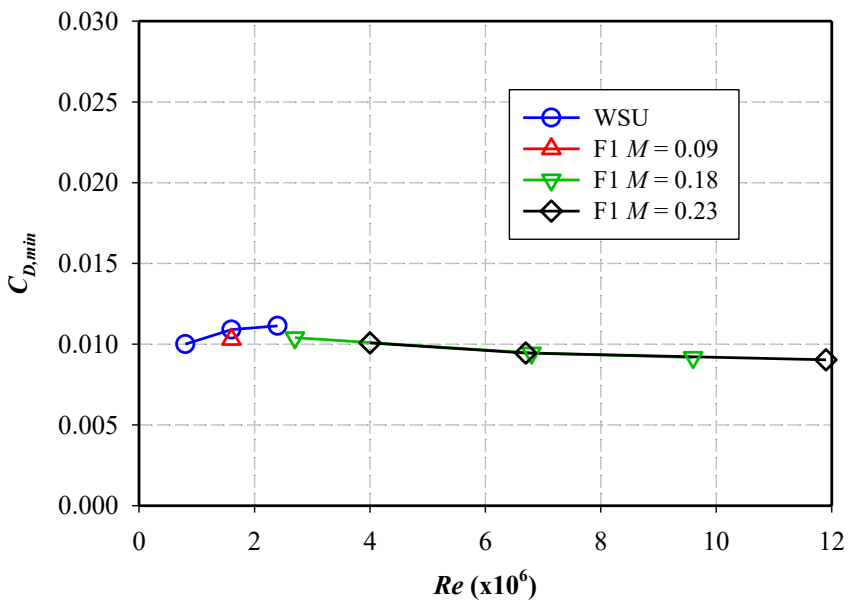

c) Minimum drag coefficient. 


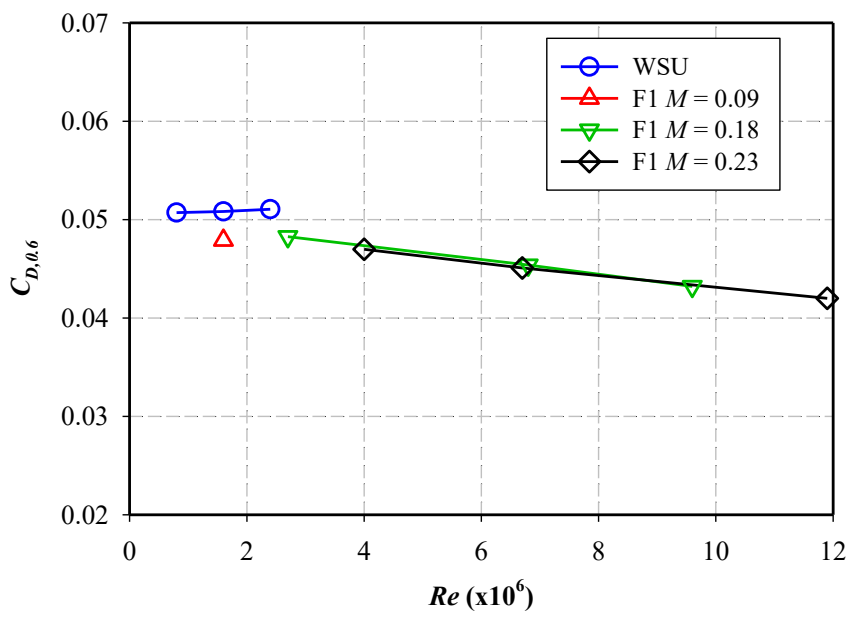

d) Drag coefficient at $C_{L}=0.6$.

Figure 19. Performance parameter comparisons with WB33 Simple Horn ice shape.

\section{WB33 Simple Horn with Grit}

Figure 20 shows the comparison of the WB33 Simple Horn ice shape with roughness grit. Figure 20a shows the comparison of the maximum lift coefficient. In the F1 data, there is no $R e$ effect and a small $M$ effect (which appeared to be smaller than the Simple Horn shape without the grit, Fig. 19a). The $C_{L, \max }$ values at $R e=1.6 \times 10^{6}$ compared better between WSU and F1 as well ( 0.88 for WSU and 0.91 for F1). The $R e$ and $M$ effects (Fig. 20b) also appears to be smaller when compared to the Simple Horn shape without the grit (Fig. 20c), but not by significant amount. The $C_{L \text {, use value }}$ comparison, however, was better at $\operatorname{Re}=1.6 \times 10^{6}(0.61$ for WSU and 0.65 for F1). This indicated that the addition of the grits made comparison of the lift values between the WSU and F1 better, but not by as much as with the WB33 Appendix C 3D Smooth ice shape (Figs. 17 and 18).

Figures 20c and 20d show the comparisons of the drag-based performance parameters. The trends shown here match very well with those from the other ice shape cases. There was no $M$ effect, and slight $R e$ effect, with the drag values decreasing with increasing Reynolds number.

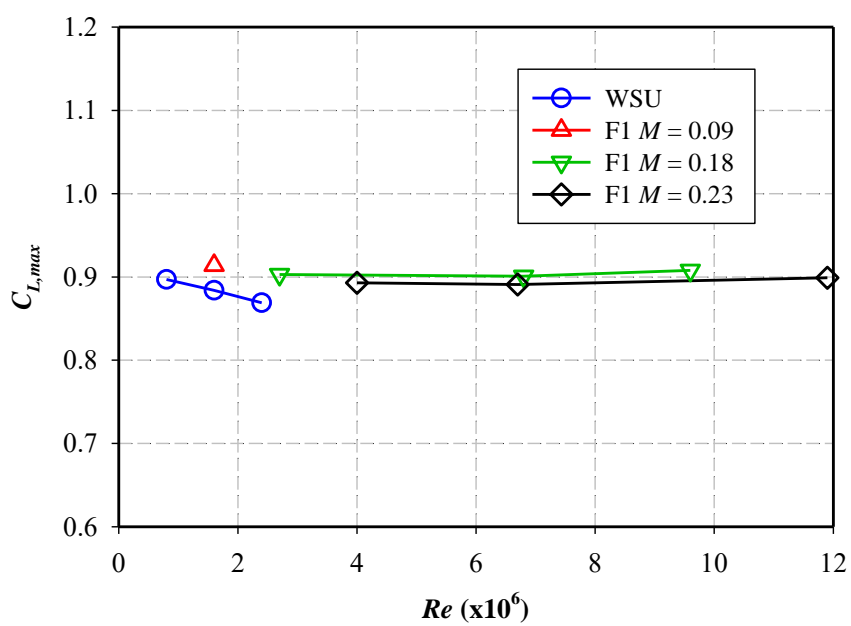

a) Maximum lift coefficient.

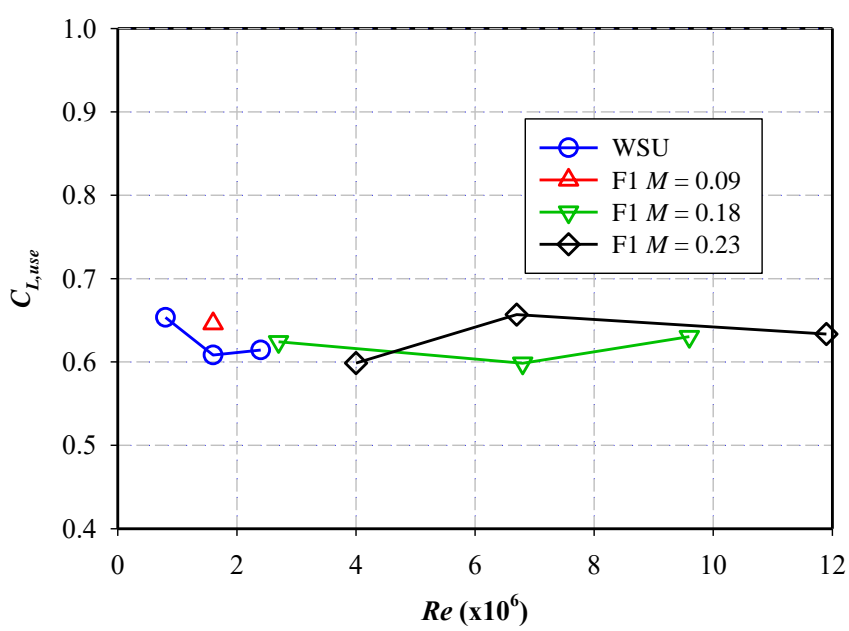

b) Usable lift coefficient.

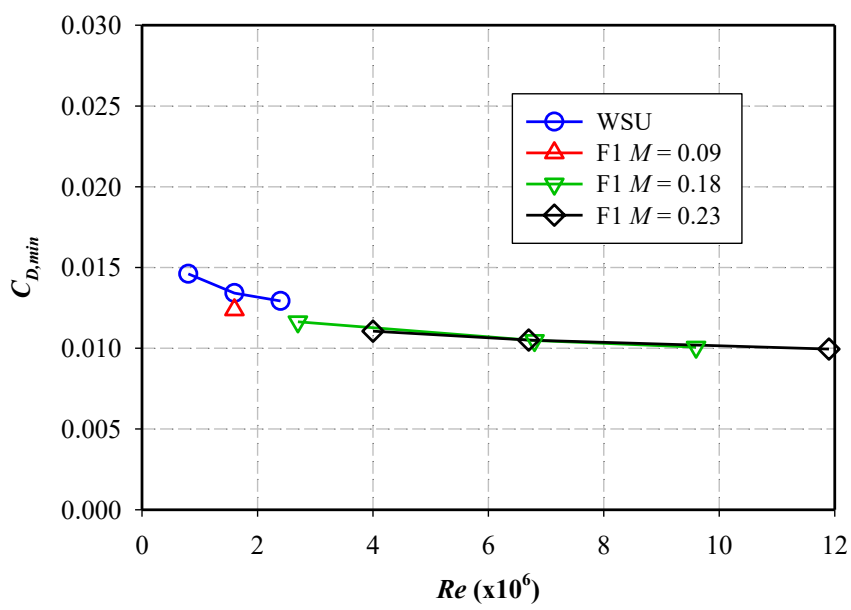

c) Minimum drag coefficient. 


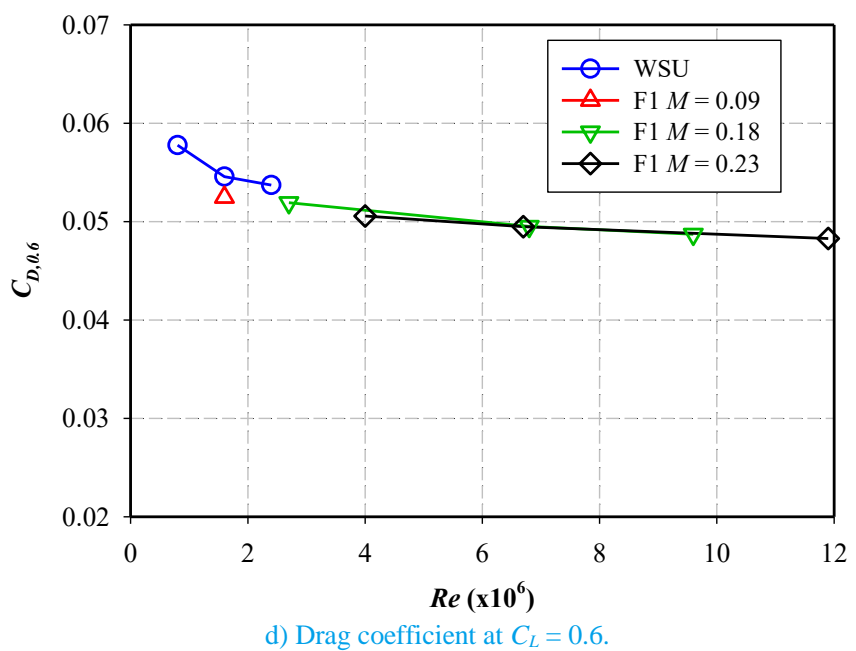

Figure 20. Performance parameter comparisons with WB33 Simple Horn ice shape with grit.

\section{Summary/Conclusions}

Artificial ice shapes of various geometric fidelity were tested on the CRM65 wing model. Low Reynolds number tests $\left(R e=0.8 \times 10^{6}\right.$ to $\left.2.4 \times 10^{6}\right)$ were conducted at Wichita State University's Beech Memorial Wind Tunnel, and high Reynolds number $\left(R e=1.6 \times 10^{6}\right.$ to $12 \times 10^{6}$ ) tests were conducted in ONERA's F1 wind tunnel. The aerodynamic performance data from the two facilities were compared at matched or similar Reynolds and Mach numbers to ensure that the low Reynolds number results from WSU could be applied to high Reynolds number. Lee, et al. [17] reported the results of the comparisons from the initial tests. This report presents the results from additional ice shape configurations that were tested since that report.

The results from tests with the additional ice shapes were consistent with the results published in Lee, et al. [17] For iced configurations, the data from WSU and F1 agreed well at matched or similar $R e$ and $M$. The lift and pitching moment curves agreed very well for most configurations. There was a $0.2-0.3^{\circ}$ offset in the angle of attack between the WSU and F1 data, possibly due to different flow angularities in the test sections of the two facilities. There was also an offset in the drag values between the two facilities from an unknown cause, but possibly due to experimental data uncertainties of F1 force balance operating in low load range.

For the iced configurations the trends observed at low Reynolds number (WSU test) could typically be extended to high Reynolds number (F1). For "3D Smooth" - type ice shapes, there appeared to be slight Reynolds and Mach number effects in the lift-based performance parameters. These effects were reduced or eliminated by applying surface roughness to the ice shape, so that the lift-based performance values found at lower Reynolds number can be used directly at high Reynolds number. There were also slight $R e$ effects in the drag-based parameters, so the trends for low Re can be applied to higher $R e$. However the drag values need to be corrected slightly to account for $R e$ effects. Overall, the data compared very well between the low $R e$ test at WSU and the high $R e$ test at F1, indicating that data from the low $R e$ test could be used to understand iced-swept-wing aerodynamics at high $R e$. These results demonstrated that swept-wing

Page 17 of 19 iced aerodynamic tests could be performed at low Reynolds number facilities (with much lower facility and model costs) and the results could confidently be applied to higher flight Reynolds number.

\section{References}

1. Morgan, H.L., Ferris, J.C., McGhee, R.J., "A Study of High-Lift Airfoils at High Reynolds Numbers in the Langley LowTurbulence Pressure Tunnel," NASA TM-89125, 1987.

2. Papadakis, M., Gile Laflin, B.E., Youssef, G.M, and Ratvasky, T.P., "Aerodynamic Scaling Experiments with Simulated Ice Accretions," AIAA 39th Aerospace Sciences Meeting and Exhibits, Jan. 8-11, 2001, Reno, NV, AIAA Paper 2001-0833.

3. Addy, H.E, Broeren, A.P., Zoeckler, J.G., and Lee, S., "A Wind Tunnel Study of Icing Effects on a Business Jet Airfoil," AIAA 41st Aerospace Science Meeting and Exhibit, Jan. 6-9, 2003, Reno, NV, AIAA Paper 2003-0727.

4. Lee, S., Ratvasky, T.P., Thacker, M., and Barnhart, B.P., "Geometry and Reynolds Number Scaling on an Iced Business Jet Wing," AIAA 43 ${ }^{\text {rd }}$ Aerospace Sciences Meeting and Exhibits, Jan. 10-13, 2005, Reno, NV, AIAA Paper 2005-1066, NASA TM-2005-213575.

5. Broeren, A.P., Potapczuk, M.G., Riley, J.T., Villiedieu, P. et al., "Swept-Wing Ice Accretion Characterization and Aerodynamics," AIAA Paper 2013-2824, June 2013, also NASA/TM-2013-216555, Sept. 2013.

6. Broeren, A.P., Addy, H.E., Jr., Bragg, M.B., Busch, G.T. et al., "Aerodynamic Simulation of Ice Accretion on Airfoils," NASA/TP-2011-216929, June 2011.

7. Vassberg, J.C., DeHann, M.A., Rivers, S.M., and Wahls, R.A., "Development of a Common Research Model for Applied CFD Validation Studies," AIAA Paper 2008-6919, Aug. 2008.

8. Broeren, A.P., Potapczuk, M.G., Lee, S., Malone, A.M. et al., "Ice-Accretion Test Results for Three Large-Scale Swept-Wing Models in the NASA Icing Research Tunnel," AIAA Paper 2016-3733, June 2016; also NASA/TM-2016-219137, Sept. 2016.

9. Woodard, B.S., Broeren, A.P., Diebold, J.M., and Bragg, M.B., "Preliminary Testing of Low Reynolds Number Aerodynamics for a Swept Wing with Artificial Ice Roughness," DOT/FAA/TC-17/48, Sept. 2017.

10. Broeren, A.P., Woodard, B.S., Diebold, J.M., and Moens, F., "Low-Reynolds Number Aerodynamics of an $8.9 \%$ Scale Semi span Swept Wing for Assessment of Icing Effects," 9 ${ }^{\text {th }}$ AIAA Atmospheric and Space Environments Conference, Denver, CO, 2017, AIAA Paper 2017-4372, NASA TM 2017-219533.

11. Broeren, A.P., Lee, S., Woodard, B.S., Lum, C.W. et al., "Independent Effects of Reynolds and Mach Numbers on the Aerodynamics of an Iced Swept Wing," $10^{\text {th }}$ AIAA Atmospheric and Space Environments Conference, Atlanta, June 2018, AIAA Paper 2018-3492.

12. Woodard, B.S., Broeren, A.P., Lee, S., Lum, C.W. et al., "Summary of Ice Shape Geometric Fidelity Studies on an Iced Swept Wing," AIAA $10^{\text {th }}$ Atmospheric and Space Environments Conference, Atlanta, GA, June 25-29, 2018, AIAA Paper 20183494.

13. Sandhu, N., Soltani, R., Bragg, M.B., Lum, C.W. et al., "Effect of Simulated Scalloped Ice on the Aerodynamics of a SweptWing at Low-Reynolds Number," AIAA $10^{\text {th }}$ Atmospheric and Space Environments Conference, Atlanta, GA, June 25-29, 2018, AIAA Paper 2018-3495.

14. Woodard, B.S., Broeren, A.P., Potapczuk, M.G., Lee, S et al., "Experimental Aerodynamic Simulation of a Scallop Ice 
Accretion on a Swept Wing," SAE International Conference on Icing, June 17-21, 2019, submitted for publication (2019).

15. Broeren, A.P., Potapczuk, M.G., Lee, S., Woodard, B.S. et al., "Experimental Aerodynamic Simulation of a Scallop Ice Accretion on a Swept Wing," SAE International Conference on Icing, June 17-21, 2019, submitted for publication (2019).

16. Soltani, M.R., Bragg, M.B., Yoshida, W., Woodard, B.S. et al., "Effects of a Low Fidelity Artificial Scallop Ice Shape on the Aerodynamics and Wake of a Swept-Wing," SAE International Conference on Icing, June 17-21, 2019, submitted for oral presentation (2019).

17. Lee, S., Broeren, A.P., Woodard, B.S., Lum, C.W. et al., "Comparison of Iced Aerodynamic Measurements on a Swept Wing from Two Wind Tunnels," AIAA Paper 2018-3493.

18. Pope, A., Rae, W. H., and Barlow, J.B. (1999). Low-Speed Wind Tunnel Testing (3rd ed.). Hoboken, NJ: John Wiley \& Sons, Inc.

19. "Data Reduction System: Boundary Corrections Three Dimensional Aircraft," Walter H. Beech Wind Tunnel Engineering Process Description, April 2014.

20. Torz-Dupuis, L., "Test NASA SUNSET II of the CRM65 Wing Model Representative of the CRM65 Wing at 1/7.5 on Half Model Set-up in the ONERA F1 Wind Tunnel," ONERA Report No. PV 4/23611 DMPE/DSFM, Dec. 2017.

21. Coleman, H.W., and Steele, W.G., Experimentation and Uncertainty Analysis for Engineers, Wiley-Interscience, New York, 1989, pp.40-118.

22. Kline, S., and McClintock, F.A, "Describing Uncertainties in Single Sample Experiments," Mechanical Engineering, Vol. 75, No. 1, 1953, pp. 3-8.

23. Camello, S. C., Lee, S., Lum, C. W., and Bragg, M. B., "Generation of Fullspan Leading-Edge 3D Ice Shapes for Swept-Wing Aerodynamic Testing," Proceedings of the 8th AIAA Atmospheric and Space Environments Conference, AIAA Paper 2016-3737, Washington D.C., June 2016.

24. Federal Aviation Administration, Advisory Circular AC 25-25A, Oct. 27, 2014.

25. Camello, S.C., Bragg, M.B., Broeren, A.P., Lum, C.W. et al., "Effect of Ice-Shape Fidelity on Swept-Wing Aerodynamic Performance," AIAA Paper 2017-4373, June 2017.

26. Furlong, G.C., and McHugh, J.G., "A Summary and Analysis of the Low-speed Longitudinal Characteristics of Swept Wings at High Reynolds Number, NACA-TR-1339, Jan. 1957.

27. Lynch, F.T., and Khodadoust, A., "Effects of Ice Accretions on Aircraft Aerodynamics," Progress in Aerospace Sciences, Vol. 37, No. 8, Nov. 2001, pp. 669-767.

\section{Contact Information}

Sam Lee can be reached at sam.lee-1@ nasa.gov.

\section{Acknowledgments}

The authors would like to thank the many collaborators without whom this work would not have been possible. Mark Potapczuk at NASA, Michael Bragg and Kevin Ho at the University of Washington, and Frédéric Moens and Emmanuel Radenac at ONERA provided key contributions to this work. The authors would also like to acknowledge the staff at the Walter $\mathrm{H}$. Beech Memorial Wind Tunnel at Wichita State University and ONERA F1 wind tunnel for their outstanding support. This work was supported through international and interagency agreements between NASA, the FAA, and ONERA. The NASA-supported portion of this research was originally funded

under the Atmospheric Environment Safety Technologies Project of the Aviation Safety Program with continued support under the Advanced Air Transport Technology and Aeronautics Evaluation and Test Capabilities Projects of the Advanced Air Vehicles Program. The Universities of Washington and Illinois were funded for this program by FAA grant 15-G-009 with support from Dr. James T. Riley.

\section{Definitions/Abbreviations}

$\boldsymbol{b}$

$c$

$x$

$y$

$C_{D}$

$C_{D, 0.6}$

$C_{D, \min }$

$C_{L}$

$C_{\text {L.max }}$

$C_{L, u s e}$

$C_{M}$

$C_{M, \min }$

$C_{p}$

CRM65

$M$

MAC

ONERA

po

$q_{\infty}$

Re

RLE

$\alpha$
Model span.

Model chord.

Model coordinate in chordwise direction.

Model coordinate in spanwise direction.

Drag coefficient.

Drag coefficient at $C_{L}=0.6$.

Minimum drag coefficient.

Lift coefficient.

Maximum lift coefficient.

Usable lift coefficient.

Pitching moment coefficient.

Local minimum in pitching moment coefficient.

Pressure coefficient.

Common Research Model $65 \%$ scale.

Mach number.

Mean aerodynamic chord.

Office National d'Etudes et Recherches Aérospatiales.

Freestream total pressure.

Freestream dynamic pressure.

Reynolds number.

Removable leading edge.

Angle of attack.

Page 18 of 19 
Sweep angle.

Page 19 of 19 